\title{
Measuring the Thickness of Metal Films: A Selection Guide to the Most Suitable Technique
}

\author{
Walter Giurlani ${ }^{1, *}$, Enrico Berretti ${ }^{2}$, Massimo Innocenti ${ }^{1}$ and Alessandro Lavacchi ${ }^{2, *}$ \\ 1 Department of Chemistry "Ugo Schiff”, Università degli Studi di Firenze, via della Lastruccia 3, 50019 \\ Sesto Fiorentino (FI), Italy; m.innocenti@unifi.it \\ 2 Institute of Chemistry of Organometallic Compounds (ICCOM) - National Research Council (CNR), Via \\ Madonna del Piano 10, 50019 Sesto Fiorentino (FI), Italy; eberretti@iccom.cnr.it \\ * Correspondence: walter.giurlani@unifi.it (W.G.); alessandro.lavacchi@iccom.cnr.it (A.L.); Tel.: +39-055-457- \\ 3102 (W.G.); +39-055-522-5250 (A.L.)
}

Received: 1 April 2020; Accepted: 12 May 2020; Published: 13 May 2020

\begin{abstract}
The determination of the thickness has a fundamental importance in all the fields in which the implementation of films and coatings are required and takes a crucial role in electroplating sector. The thickness influences many aspects of the coatings such as electrical, mechanical, corrosion protection and even aesthetical properties. In the multitude of applications of thin layer coatings, the variability of thicknesses and materials is very high as well as the possible techniques that can be used to determine the characteristics of the layers of interest. The first distinction that can be made between these techniques is that which divides destructive techniques from nondestructive ones, in which however the semi or micro-destructive techniques are immediately difficult to place. Other important parameters to consider are the cost, both for the purchase of the instrumentation and for each single analysis, the difficulties in preparing and measuring the sample and data processing and obviously the detectable thickness ranges, the possible measurable materials, precision and accuracy. The purpose of this work is to compare the characteristics of the various investigation methods, with a particular focus on metal films applications, so that it will be easier to choose the most suitable technique for each purpose.
\end{abstract}

Keywords: thickness determination; thin film; material characterization; metal coating; cross section; optical microscopy; SEM; FIB; EDS; XRF

\section{Introduction}

The use of thin films has become a ubiquitous practice in many scientific and industrial sector. Coatings are widespread used to obtain a synergistic action between the characteristics of the substrate and the covering material to improve the physical, chemical and aesthetic properties and to lower the costs of the final product. For this reason, the measurement of the thickness in composite materials is mandatory both to obtain the right characteristics in the final artefact as well as to keep the costs under control. The composition of the films could be extremely vast: dielectrics (organic, such as polymers and self-assembled monolayers (SAM), or inorganic, like metal oxides), semiconductors and metals are all used in the form of films, obtaining a composite material with combined characteristics. In this work, we focused on the metal film characterization obtained through electrodeposition or vapour phase deposition but in most of the cases the same principles can be applied to films of different materials. As far as the films dimensions is concerned, the thinnest measurable thickness coincides with an atomic monolayer (ML), while the thicker layers could reach hundreds of microns in electroforming. Therefore, in this review we made an overview of all the techniques that allow to investigate in this range. 
According to the type, the composition and the thickness itself of the film and the substrate, various techniques could be employed to investigate the size of the layers [1], but all the methods could be classified in two different categories: destructive and non-destructive techniques. Within the various techniques, both the methods of sample preparation and the actual analysis methods are distinguished. In fact, a sample can be prepared with a certain procedure, for example by making a cross section and then analysed with different instrumentations such as optical or electronic microscopy. Of course, there are also self-consistent techniques which require no sample preparation, or minimal preparation.

A destructive technique is a method that alters the sample, generally by scratching it, at a macroscopic or microscopic level; therefore, the analysed piece cannot be put on the market and it must be destroyed instead. This means that we must be sure about the conformity with sale of the unmeasured objects. On the other hand, a non-destructive technique permits to measure the sample without damaging it but, generally, if it belongs to the group of indirect measurements, requires some assumption and calculation to be performed to obtain a numerical value of the thickness.

The preparation methods, covered in this review, are the cross sectioning, TEM lamella preparation, angle lapping and Calo test. Cross sectioning and Calo test are macroscopic methods while TEM lamella preparation, angle lapping are microscopic procedures performed with a focussed ion beam (FIB). In any case, all of them are destructive and are needed before any microscopic analysis whether it exploits light, such as optical microscopy; electrons, in the case of scanning electron microscope (SEM) (with both backscattered (BSE) and secondary (SE) electrons), transmission electron microscope (TEM) and scanning transmission electron microscope (STEM); ions, e.g. scanning ion microscopy (SIM).

Other destructive preparation method involves masking the sample to leave the substrate partially uncovered to analyse the heights profile of the sample with a profilometer [2] or atomic force microscopy (AFM) profilometry [3].

Other analytical techniques are self-consistent, and they only require that the sample surface be properly cleaned. These techniques analyse the sample along the direction perpendicular to the surface instead of using a lateral view of the cross-section and even in this case a there are representatives of both the two groups of destructive as well as non-destructive methods. Respect to the microscopy techniques, these ones does not give a direct information about the thickness and the signal must be analysed to deconvolute all the information that contains. For this reason, we must know as much information as possible about the sample to make the right assumptions on its nature and obtain reliable results. The X-ray fluorescence spectroscopy (XRF), in addition to being an excellent technique for compositional determination, is by far the most common technique used in the industrial field for thickness measurement and quality control as it allows fast, non-destructive analysis and with minimal sample preparation [4]. In addition to that, with XRF practically all the elements of the periodic table can be analyzed, except for the lighter ones (if not with some precautions), whether conductive or not. The thickness can be extrapolated from XRF data by means of standards [5], using the analytical equations of fundamental parameter method (FP) [6] or through Monte Carlo (MC) simulations [7,8]. Other non-destructive techniques, more commonly used for research purposes, are ellipsometry [9], which however is rarely applicable to metallic coatings are generally not optically transparent, and X-ray reflectivity (XRR) $[10,11]$ that can detect thicknesses from tens of nanometres to some micrometres. Although they are commonly used for quantification purposes even electron probe microanalysis (EPMA) [12,13] and X-ray Photoemission Spectroscopy (XPS) [14-16] could be employed to determinate the thickness information up to the atomic scale. The methods used for the deconvolution of the signal range from the use of standards [12,17], Monte Carlo (MC) simulations [18-20], attenuation length [21,22] and three-layer-model or multilayer model analysis [23-28]. Also Rutherford backscattering spectroscopy can be used for the determination of films thickness $[29,30]$. Furthermore the thickness of a coating can be determined by destructive sputtering techniques [31] with which the sample is bombarded with ions, the surface is slowly removed and the elements emitted by it analysed by carrying out a depth profiling analysis. are part of this group secondary ion mass spectrometry (SIMS) [32,33], and XPS sputtering using a fixed angle 
or an angle resolved XPS (ARXPS) and performing the reconstruction of the thickness with Laplace transform or maximum entropy method [34-38].

\section{Destructive Techniques}

\subsection{Preparation Methods}

\subsubsection{Mechanical Cross-Sectioning}

The cross-section technique is very widespread and relatively simple to use even if it requires particular attention and manual skill of the operator, in fact if not executed with attention it can lead to inaccurate measurements. It consists in cutting the sample in half and observing it transversely, along the profile of the layers whose thickness must be measured. This technique therefore allows to directly measure the thickness of the film through a ruler. The entire analysis process consists of three steps: sample preparation (cutting, embedding and lapping); microscopic analysis, through optical or electronic microscopy; data processing, through dedicated software to convert the image dimensions from pixels into a unit of length through a scale.

The sample preparation process is the most critical and time-consuming step; it is during this stage that artefacts that could invalidate the subsequent analysis could be generated. Usually the sample is sawn using a disc cutting machine with the use of an abrasive resin disc or a diamond disc but, if the sample allows it, it can also be cut in other ways such as with a cutter or scissors. The cut must be made perpendicular to the surface, otherwise the thickness analysed will be overestimated due to the parallax error. In addition, the cut must neither be too fast nor overheat the sample in order to avoid damaging or detaching the film, for this reason many saws are equipped with a liquid cooling system with a direct jet on the sample.

If our interest is to accurately measure the thickness of the outermost film, and this is very thin, the cut could compromise the analysis. To avoid this problem, if the sample is conductive, it can be covered with a galvanic deposition of a few microns in order to protect the layer of interest. Alternatively, the sample can first be incorporated in resin and then cut later but in this case, it is more complex to perform a cut perpendicular to the surface. Moreover, the hardened resin tends to shrink, remaining not perfectly adherent to the sample and reducing the protection of the external film.

The incorporation can be performed with both hot melt and cold resins. The sample is placed in a housing ensuring that it is perfectly level and the resin is poured being careful not to leave air bubbles. The resin used can be both conductive and non-conductive. If the sample will be analysed under an optical microscope, there is no difference, therefore non-conductive resins are preferred because they are cheaper. On the other hand, if it will be carried out electronic microscopic analysis, a conductive resin is preferable to avoid polarization phenomena, but a non-conductive resin can also be used if it is possible to graphitize the sample.

The last step in sample preparation is lapping. Near the cut the sample will inevitably be damaged and the films will be altered: there could be both the peeling, meaning the detachment of the less adhered films, and a spreading of the softer films. The lapping process is the longest phase, it can take several hours, and consists in polishing the section of the sample with gradually finer abrasives until a mirror surface is obtained. The surface roughness and scratches must be minimized in order to accurately measure the thicknesses, as a rule of the thumb the surface roughness, and consequently the abrasive grain size, must be in the order of magnitude, of the thickness to be analysed or less, generally 1-0.3 micron. The lapping process can be carried out by hand or using special automatic lapping machines. A wet abrasion is carried out first using sandpaper, gradually finer and then with a cloth soaked in an abrasive suspension. The suspended particles can be alumina or diamond dust. Initially, with a sufficiently coarse sandpaper, all the part that was damaged during cutting is removed, about $1 \mathrm{~mm}$ in depth; then the mash size of the sandpaper is decreased. A fine grain size is not used immediately because otherwise it would not be possible to remove the deepest scratches. In the event of lapping by hand, the sample must not be pressed too hard and care must 
be taken not to consume one side more than the other to avoid introducing a parallax error. For this reason, it is advisable to rotate the sample in the same direction as the lapping machine disk and occasionally turn it of $90^{\circ}$ with respect to its normal axis. When you think that the sample is ready, it is washed and inspected visually or, if available, under an optical microscope to check that all the scratches have been flattened, if the sample is sufficiently smooth, the next phase of microscopic analysis can be carried out. For example purposes, a microscopic analysis of the same cross-section is shown in Figure 1, where a comparison between optical and electron microscope have been carried out image. The multilayer sample is made of brass $/ \mathrm{Cu} / \mathrm{bronze} / \mathrm{Pd} / \mathrm{Au} / \mathrm{Ni}$. With the optical microscope it is possible to distinguish most of the layers, even the thin gold layer is visible although not quantifiable, but it is not possible to discriminate between the bronze and palladium layers. The layer with thickness over $500 \mathrm{~nm}$ can be measured with the optical microscope but for thinner coatings, and to distinguish brass and palladium the electron image is necessary.

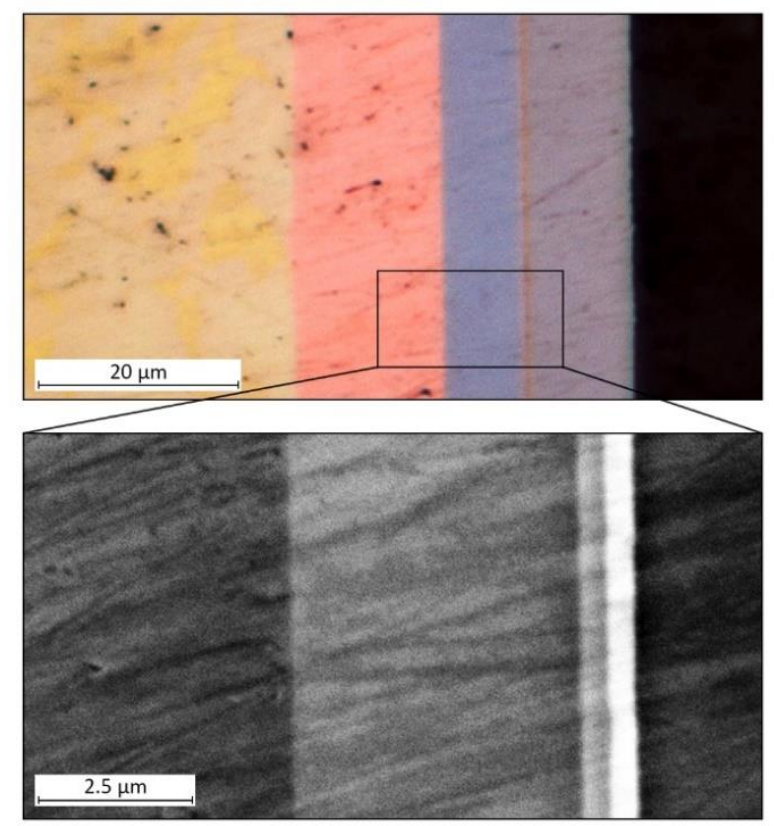

Figure 1. Cross section multilayer sample (brass/Cu/bronze/Pd/Au/Ni) observed with optical microscope (top) and electron microscope (bottom).

\subsubsection{Ion Beam Cross-Sectioning}

Cross sectioning procedure can be performed also by focused ion beams. By exploiting the sputtering effect of FIBs, it is possible to raster a surface producing precise trenches, useable to observe the in-depth evolution of the sample [39]. The trench dimensions can vary from $\mathrm{mm}$ (for a Xe or Ar plasma FIBS) to less than $1 \mu \mathrm{m}$, whit a maximum depth in the range of hundreds of microns. Due to the small dimensions of the holes produced on the surface, this process (unlike mechanical cross sectioning) can be considered as semi-destructive. This process is also fast in respect to mechanical cross sectioning, because it permits to produce clear cuts from which is possible to characterize the profile of a sample in 20-60 minutes (depending on the size of the hole). For these reasons, it is particularly well suited for the characterization of thin films having thicknesses below $10 \mathrm{~nm}$. The subsequent characterization step can be performed by SEM or SIM microscopy, or EDX analysis due to the small hole dimensions.

Even if the cross-sectioning process can be performed only by using a FIB for a coarse determination of thick films, films down to $10 \mu \mathrm{m}$ will require the use a FIB/SEM equipped with a Gas Injection System (GIS). This because, in order to avoid FIB-induced surface degradation, a thin protective layer above the surface is needed. This can be achieved only by using a beam deposition process achievable by the presence of a GIS. In FIB/SEMs the protective layer is produced by a two- 
step deposition process. First, a thin layer of metal is deposited on the surface using the electron beam (e-beam deposition). Then, a thicker metallic layer is deposited using the ionic beam (i-beam deposition). The e-beam deposition avoids surface degradation (and thus loss of thickness information on the topmost layer) due to direct impingement of the ionic beam on the surface [40]. The full workflow for the preparation a cross section using a FIB can be visible in Figure 2.

a) Starting set-up

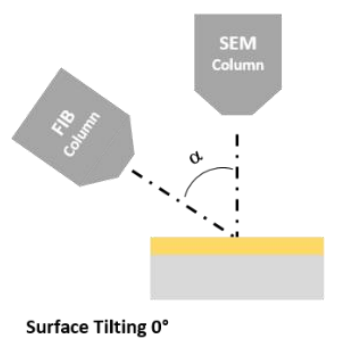

b) e-beam deposition

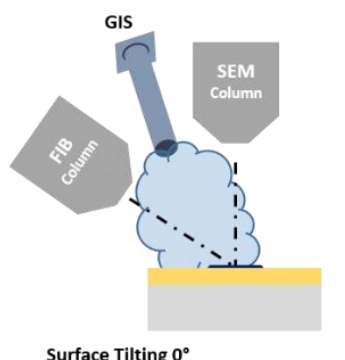

c) i-beam deposition

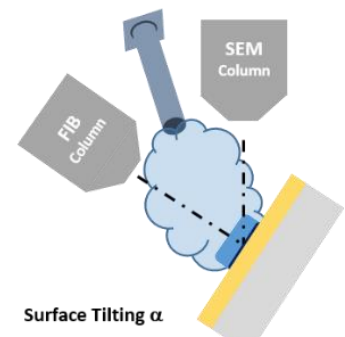

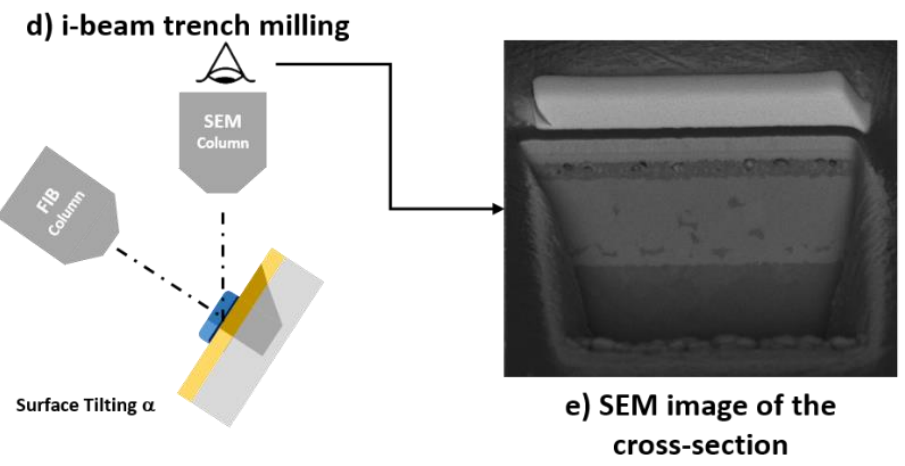

Figure 2. An example of FIB cross-sectioning workflow.

\subsubsection{Angle Lapping}

Angle Lapping is a sample preparation method used to increase the resolution in thin film thickness determination of the adopted microscopy characterization technique; it is based on a change in cutting geometry in respect to cross-sectioning (Cap.2.1). During traditional preparation procedures, in order to unshed the stratigraphic information from the sample, the cutting plane is perpendicular to the surface $\left(\theta_{\text {cut }}=90^{\circ}\right)$ [41]. The uncovered section gives direct stratigraphic information on the displacement and thicknesses of the layers above the substrate. Instead, in Angle lapping, the sectioning cut is performed at very low angles in respect to sample surface $\left(\theta_{\text {cut }}<10^{\circ}\right)$. This produces a "magnification effect" on the newly created section surface, on which all the layers appear stretched. Knowing the cutting angle, and a bit of trigonometry, is consequently easy to derive the film thickness. The main advantage of this method is the magnification effect, which allows to overcome resolution limits of the microscopic technique adopted for the quantification, even for very thin films. As a prerequisite, a very flat film surface is mandatory for a precise determination of the thickness of the layers underneath; moreover, particular care must be put in preparation of the surface after the cut. It is uncommon, especially for mechanically machined soft materials, to incur into thin film deformation onto the cutting surface [42]. The origin of this sample preparation technique comes from the first metallographic studies, and it is still considered as a valuable method to overcome the resolution limits of the adopted microscopic characterization methods, and its adoption has shifted to FIB cross-sectioning or lamella preparation, enabling fine characterization of ultrathin films. It can be used before both optical microscopy and SEM characterization. 


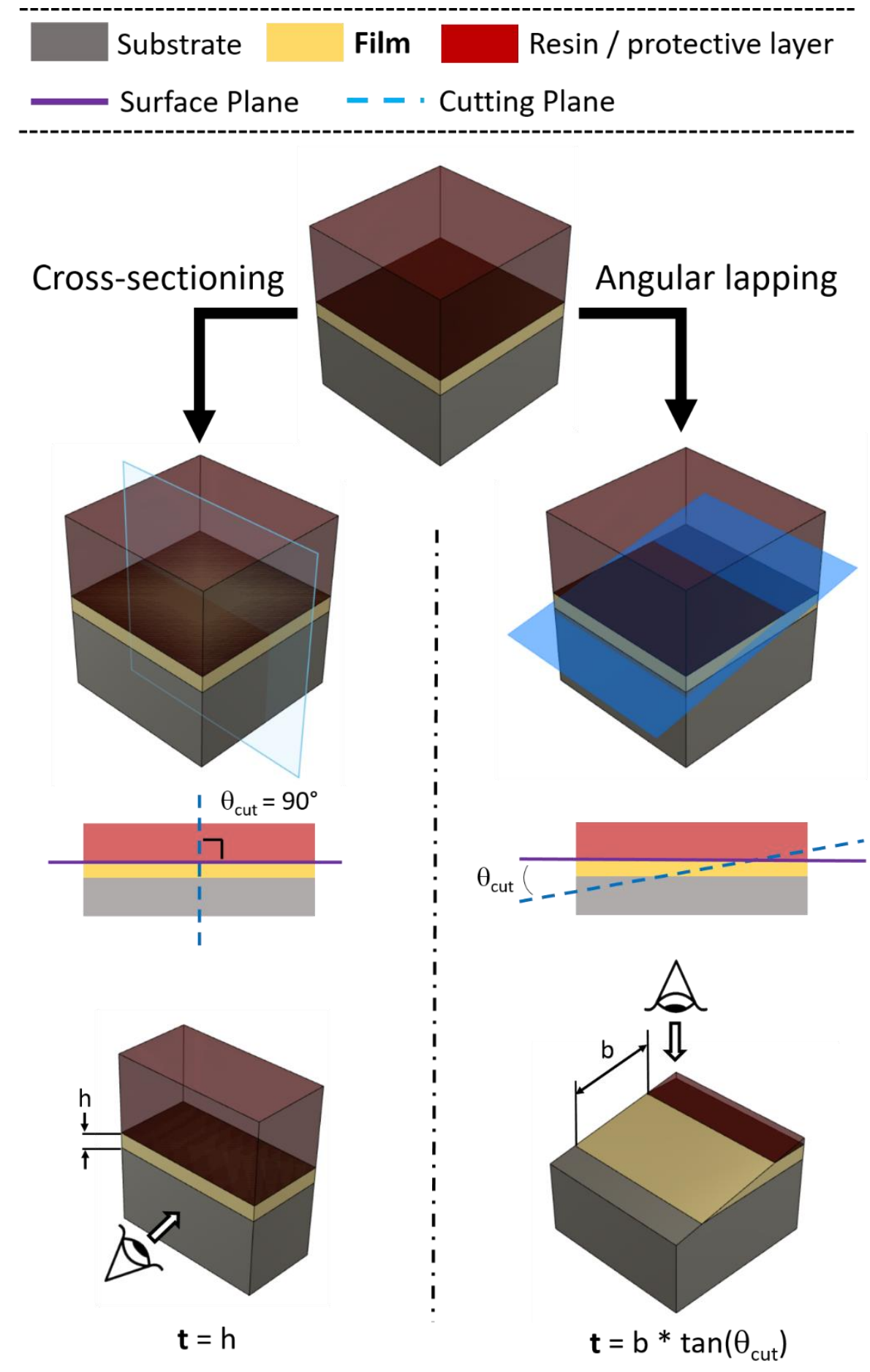

Figure 3. Comparison between film thickness determination: traditional Cross-sectioning (left column), and angle lapping (right column).

\subsubsection{Calo Tester}

The Calo tester, also known as ball craterer or crater grinding, is a semi-destructive technique that is not very widespread but extremely practical in some cases, in addition it is regulated in ISO 26423 [45] (Ex EN-1071 and VDI 3198 [46]). Compared to the cross section, it has the advantage of being only locally destructive, therefore the sample, instead of having to be cut in half, is excavated in an area with a diameter of about one millimetre $[47,48]$. Furthermore, the whole analysis is much faster as the sample does not have to be incorporated and lapped. 
This technique consists in fixing the sample on a variable angle support; on it is placed a steel sphere covered by an abrasive suspension; the sphere is in contact also with a rotating cylinder that makes it roll (Figure 4). Within a few minutes, depending on the hardness of the sample and its angle of inclination, that is translated to the weight that the sphere impresses on it, a circular crater will form revealing all the layers [49]. Since the abrasion angle is very low (due to the diameter of the sphere), layers of even a few microns will have a much greater apparent size and can be appreciable under a normal optical microscope. Obviously, as in the case of the cross section, only the layers having a different colour can be distinguished. Once the diameters of the concentric circles that have been created on the sample have been measured, using a dedicated formula (Figure 4) that takes into account the diameter of the abrasion sphere, the real thickness of the films can be obtained. Manufacturers ensure that the range of thicknesses that can be measured are between 50 and 0.1 microns.
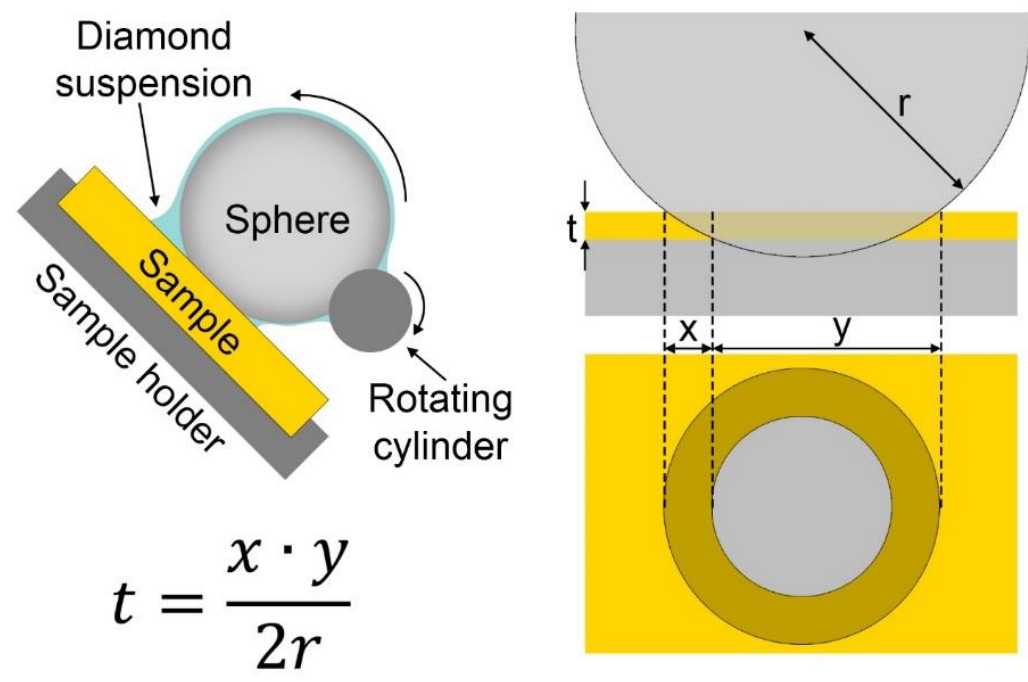

Figure 4. Experimental setup, working functionality and equation to calculate the film thickness with a Calo tester.

\subsubsection{TEM Lamella Preparation}

The ultimate procedure for thickness determination of thin films is represented by the TEM lamella preparation process. It is in fact possible to extract a small portion of the sample surface, usually a $10 \times 5 \times 1$ micron solid, containing the surface cross section. This lamella can then be thinned down to less than $100 \mathrm{~nm}$ in order to be observed transversally by TEM or STEM [43,44]. Due to This preparation process is important for the characterization of very thin films (below $1 \mu \mathrm{m}$ ) using SEM and TEM. The small thickness of the lamella decreases abruptly the interaction volume, cutting down the signal coming from in-depth SE and BSE. To prepare a TEM lamella, a FIB/SEM equipped with a GIS and a nanomanipulator is required. Moreover, the lamella preparation process is quite complex, and is constituted by numerous steps that can vary depending on the load-out of the adopted machine and the geometry of the sample chamber. Generally, the workflow can be divided in three main stages: In the first stage the lamella is shaped (carved) directly onto the surface of the sample. In the second stage, called lift-out, the lamella is detached from the sample, and is mounted on a TEM support grid. In the third stage the lamella is finally thinned down to enable transmission electron analysis. This last process is crucial for the obtainment of defect-free lamellas. In Figure 5 an example of a workflow for a Tescan GAIA 3 FIB/SEM is shown: a) a raw lamella (about $10 \times 5 \times 1$ microns) is carved on the surface, b) an undercut is performed in order to detach the lamella, c) nanomanipulator is moved on a side of the lamella and soldered to the body, then the lamella is detached from the surface, d) e) and f) lamella is moved from the surface of the sample to the TEM support, g) lamella is soldered to the support, h) nanomanipulator is detached from the lamella, i) 
lamella is thinned down until electrontransparence, $\mathrm{j}$ ) in the end lamella quality is tested using the microscope in-built STEM detector.

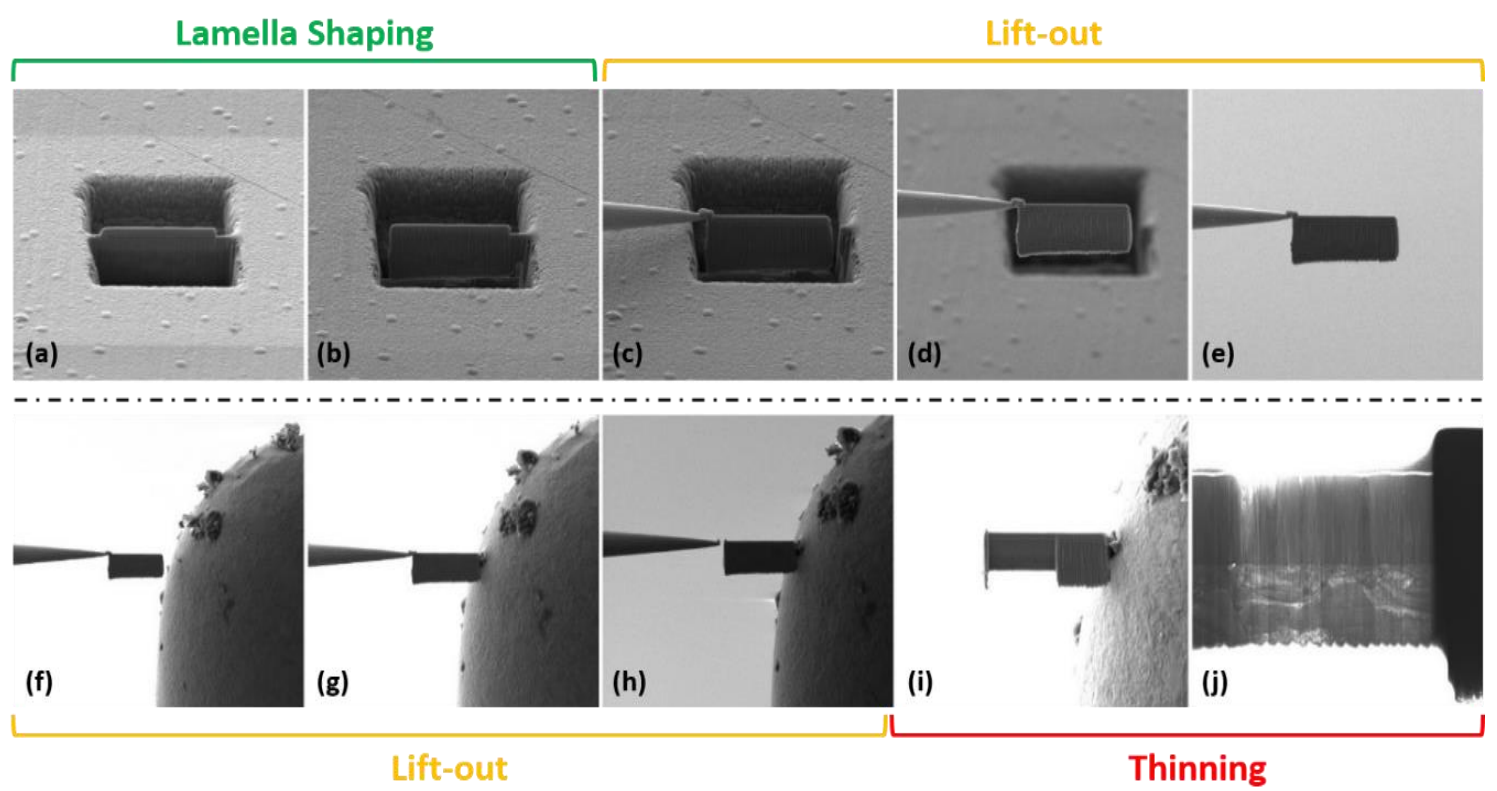

Figure 5. SEM images of the main steps regarding TEM lamella preparation.

\subsection{Microscopic Analysis}

\subsubsection{Optical Microscopy}

In order to measure a cross section of a sample it is necessary to use the microscope in reflection mode; additionally, to be able to recognize the different layers it is necessary that they have a sufficiently high contrast, or more simply different colours. Distinguishing different layers made, for example, of the same silvery metals, is impossible, while it is very simple to measure, for example, a silver film on copper or brass.

The lateral resolution, i.e. the minimum distance between two resolved points, is defined by the Abbe principle. The resolution is related to the wavelength of the source used, in this case the visible photons. The theoretical resolution of an optical microscope, not taking into account optical aberrations, using white light is about 0.2 microns. However, more realistically, the measurement of films with a thickness of less than one micron is difficult and with a consistent uncertainty [50-53].

\subsubsection{Electron Microscopy}

Scanning electron microscopy (SEM) is used when the thicknesses are too small to be analysed with the optical microscope or if the layers have too low contrast among them. As a general rule, if the cross section of a sample can be adequately analysed with an optical microscope, there are no valid reasons to use an electron microscope, in fact, the sample needs some characteristics in order to be measured with an SEM; moreover, SEM analysis is intrinsically more expensive than a simple optical analysis. Despite this, for most coatings optical microscopy is not enough to obtain adequate results. A sample that is analysed by SEM must be stable in high vacuum (about 10-7 bar), must be stable when irradiated by an electron beam and must be conductive. These limitations can be circumvented by means of some tricks: there are specific environmental or low-vacuum SEM which allow analysis to be carried out with a pressure in the order of one Pascal; the acceleration potential of the electron beam can be reduced to a few $\mathrm{kV}$ in order not to damage the sample, but decreasing the signal-to-noise ratio; non-conductive samples can be graphitized to avoid the accumulation of surface charges that in this way are dispersed to ground. However, these problems arise when 
biological, organic or polymeric samples are analysed, for metallographic cross-sections there are rarely complications of this type.

Numerous advances have been made in the last few decades in the field of electron microscopy and the resolution of these instruments is quite variable and ranges from about $20 \mathrm{~nm}$ for older instruments with thermionic emission, up to falling below the nanometre scale for new instruments with field emission source (FEG-SEM). In SEM, the main limit to the resolution is not so much the wavelength of the probe, the electrons, as the diameter of the beam and therefore its focus and collimation. For this reason, a stratagem to improve the resolution consists in bringing the sample closer to the source, reducing the working distance and consequently the opening of the electronic cone. The SEM images can be acquired using secondary electrons (SE), backscattered electrons (BSE) or through a microanalysis map (EPMA). Because of the different nature of the signal they differ in the depth from which the signal comes (Table 1) and in their volume of interaction (Figure 6). A higher volume of interaction results in a lower lateral resolution and translating in a less clear separation of the edges between the films that have to be analysed [1,13].

Table 1. Penetration depth of SE, BSE and EDS in Al and Au with a $20 \mathrm{kV}$ beam.

\begin{tabular}{cccc}
\hline $20 \mathrm{kV}$ Beam Penetration Depth & SE & BSE & X-Ray \\
\hline $\mathrm{Al}$ & $50 \mathrm{~nm}$ & $700 \mathrm{~nm}$ & $2000 \mathrm{~nm}$ \\
$\mathrm{Au}$ & $5 \mathrm{~nm}$ & $70 \mathrm{~nm}$ & $200 \mathrm{~nm}$ \\
\hline
\end{tabular}

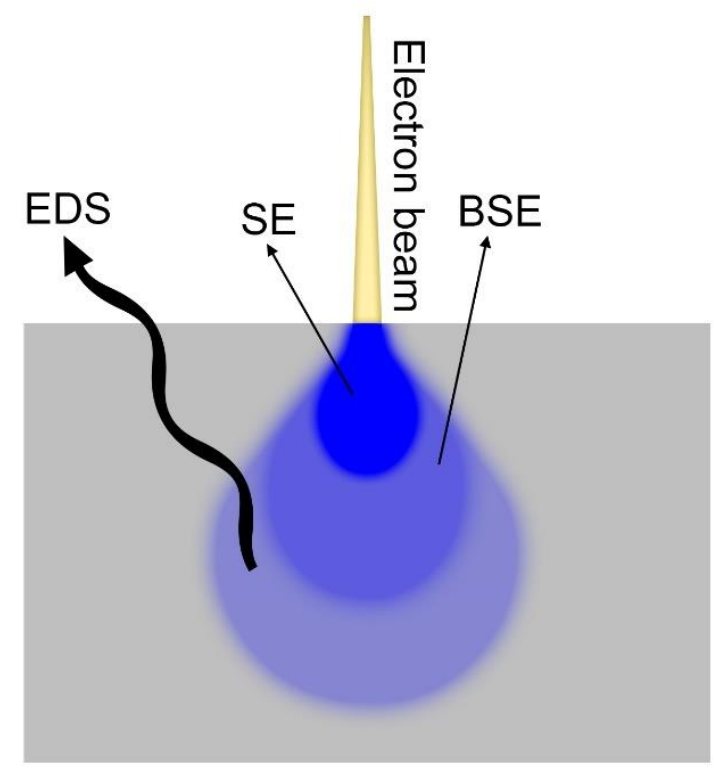

Figure 6. Volume of interaction of SE, BSE and EDS.

SEs are produced when a primary electron, from the beam, excites an electron of the atoms of the sample to the point of tearing it from the nucleus, these electrons are low in energy $(<50 \mathrm{eV})$ and only those generated most superficially on the surface are detected. SEs carry the morphological information with them, so the contrast in the image is based on the heights of the sample. Since our sample has been levelled, the contrast produced can only be due to the different nature of the material. The SE in small part also contain information also on the composition since the quantity of electrons emitted is proportional to the atomic number of the element under the electron beam. Thus, layers of elements with significantly different atomic numbers can be distinguished [54,55]. A trick that allows to observe similar elements with the SE is to chemically etch the sample before the analysis, to slightly corrode one material compared to another, in this way morphological differences, clearly visible to the $\mathrm{SE}$, are reintroduced between the different layers. However, the etching must be studied appropriately with respect to the sample that have to be analysed. 
BSEs are the primary electrons which, interacting with the positive nuclei of the atoms of the sample, are back scattered towards the source, for this reason they are very energetic and penetrating. Therefore, BSE carry mainly compositional information: heavier elements generate more BSE. By sacrificing part of the lateral resolution, the image obtained will be much more contrasted by highlighting differences between the layers that can be below an atomic number unit for more modern systems, allowing in some cases to distinguish even deposits of a metal from its alloy (for example copper on brass).

Finally, the EPMA signal can be used. This is the signal with the highest volume of interaction and for this reason the lateral resolution is very poor when compared with the previous ones. In this case, to be analysed are not the electrons but the $\mathrm{X}$ photons that are emitted from the sample after the interaction with the primary electrons, which ones contain detailed information on the composition. With EPMA, alloys can be distinguished which vary in composition by a few percentage points. Then the different layers can be highlighted by making a map, or a linear scan perpendicular to the layers. However, given the low lateral resolution, films just below the micron are difficult to quantify.

Another trick to increase lateral resolution is to reduce the volume of interaction and this is possible by decreasing the energy of the electrons by lowering their acceleration potential. This greatly reduces the signal but with modern instruments it is possible to obtain good images using acceleration potentials of only a few $\mathrm{kV}$. This strategy is very limited, however, in the case of the EPMA since, in order to have a good emission of the $X$ photons, the electron beam must have indicatively an acceleration potential once and a half times the energy of the emission peak of interest.

\subsubsection{Focused Ion Beam Methods}

Another series of techniques enabling fast characterization of thin metallic films relies on the use of focused beams of ions. Ionic probes, display different beam-matter interaction in respect to electrons, resulting in different effects of the impinging beam on the surface [56-61]. When a focussed ion beam (FIB) hits a surface, it can generate a series of different effect in respect to an electron beam; all these effects are a consequence of elastic or inelastic collisions between the charged particles and the atoms forming the surface. The most important interactions can be listed: a) Surface sputtering and secondary ion emission, b) deformation of the surface reticule, c) ion implantation, d) emission of electrons, e) emission of electromagnetic waves and f) heating. All these effects manifest at the same time, but their ratio is strongly dependent on the physicochemical nature of both the probe and targeted surface, and on the apparatus set-up. For a certain ion source, parameters such beam energy, beam current, and impact angle can be tailored to favour one phenomenon in respect to the others. Among all the ion beam-matter interactions, two are widespread used for the characterization of thin metallic films: a) the production of electrons [62] and c) the sputtering and secondary ion emission [63] . The first one exploits a signal which is similar to the one responsible for SEM images, while the second permits to perform subtractive manufacturing onto the surface. FIB apparatus could in fact perform both sample preparation and analysis in a single workflow, by preparing the surface cross section and acquiring its images, though not all the FIB columns are fitted to perform well both the processes. As already mentioned, different elements could be used as ion sources; their charge/mass ratio could modify deeply the ratios at high sputtering and SE production manifest. Today, the main commercial FIB machines are engineered to work using He, Ga, Ar or Xe ions [64]. Smaller ions, like $\mathrm{He}$, are well suited for imaging purposes, while bigger ions like Ar and Xe are used for fast sputtering; Ga FIB machines are considered a good trade-off between the two effects and are still considered as the best choice for all purpose tasks.

From a technical point of view, FIB machines are very similar to SEMs. In both of them, we have a column that can be divided in: a) a top part composed by the source, responsible for the ion/electron generation and b) a bottom part, the focusing apparatus, a series of electrostatic/electromagnetic lenses, condensers and apertures to focalize and control the beam [57]. In FIBs, the working principle exploited for ion emission varies depending on the physicochemical properties of the element of choice; we could divide the sources in three main branches: Gaseous Field Ionization Sources (GFISs) for He [65], Liquid Metal Ion Sources (LMISs) for Ga [57] and Plasma sources for Ar and Xe [66,67]. 
Despite SEMs, in FIBs the focusing apparatus is composed by electrostatic elements (lenses, condensers, etc.) rather than electromagnetic. Ions in fact suffer weakly by Lorentz forces due to their slower travelling speed (in respect to electrons) in the column, meaning also that these instruments are less prone to suffer from stray external magnetic fields. Ion sources are not interchangeable; the focusing apparatus must be finely engineered to suit for the particular physical properties of the source element. This means also that the choice between different FIB machines, exploiting different sources, must be carefully planned in respect of the need. Historically, industrial FIB columns were intended as standalone instruments, these devices were diffused especially in the semiconductor/ electronic industry, where their use both for quality check and prototyping falls back from the "70s. Today FIBs can be found easily when paired whit a SEM column [68]. This double column configuration allows a vast array of different procedures for the characterization of materials in the range of $\mathrm{mm}$ down to the $\mathrm{nm}$ for all $\mathrm{R} \& \mathrm{D}$ fields. FIB/SEMs can be equipped with a vast array of accessories and sensors to enable different characterization techniques. Among the available accessories, the gas injection system (GIS) has a particular relevance, because permits additive manufacturing in the range of tens of $\mathrm{nm}$ using both the ionic and the electronic beams. The GIS is constituted by a series of external reservoirs containing the precursors of the elements we want to deposit onto surfaces, which are heated to produce a reactive gas. This gas is injected by a hollow needle in the vicinity of the surface of the sample, where it forms a cloud between the beam and the surface. The beam particles hitting on the precursor produce the degradation of the molecules, followed by precipitation of the elements onto the surface. It is possible to use both the electron beam (e-beam deposition) or the ionic beam (i-beam deposition) [69] to achieve deposition. In the following paragraphs the main techniques which can be exploited for metallic layer thickness determination will be presented: an analytical technique (Scanning Ion Microscopy) and two preparation techniques (TEM lamella preparation and angle lapping). All the FIB methods are well suited for the characterization of metallic films of thicknesses ranging from $50 \mu \mathrm{m}$ to $10 \mathrm{~nm}$.

\subsubsection{Scanning Ion Microscopy}

Scanning Ion Microscopy (SIM) can be used as an alternative to SEM for the study of cross sections obtained by mechanical methods. The main advantage in using charged atoms instead of electrons is related to the smaller ion mean free path inside the matter $[65,70]$. This effect is responsible to a smaller beam-surface interaction volume, to a higher number of surface SEs, and thus to crispier images. Moreover, the number of SEs produced per impacting Ion is much bigger in respect to the number of SEs produced by the impact of an electron, greatly enhancing the brilliance of the signal [71]. Ions are also particularly sensitive to crystal orientation; images acquired by this method tend to possess strong crystalline contrast due to enhanced channeling effect [72]. Ionic imaging can be performed using the same SEM SE detector, whit a lesser lateral resolution in respect to electrons.

\subsubsection{Data Analysis}

Once the image is obtained with a microscopic technique, the pixels must be converted into a unit of length. Most of the software that allow to acquire microscopic images (both optical and electronic) commonly have a tool for the extraction of this information, otherwise there are free or paid software that allow to do the same job as ImageJ, Gimp and Adobe Photoshop to name the most known. In order to convert the pixels to length on the image, a reference scale must be printed on it, through that scale we can get all the dimensions of interest in the image. The thickness of the films can therefore be measured, being careful to carry out the measurement perpendicular to the film. By making the measurement in several points, a statistic of the thicknesses can also be carried out. However, in the event that the edges of the film in the image are not very defined, finding the limits by eye could be complex, as showed in the blur image of a Au film reported in Figure 7. In these cases, instead of analysing the image, it is more practical to observe the profile graph in which the greyscale values are reported. If the different layers have contrast between them, they also have a 
different grey value; the delimitation between one layer and another can be defined as the point where the value is intermediate between the two layers or, more rigorously, at the inflection points of the graph. In this case the spatial resolution, and therefore the uncertainty of the measurement, is defined as the distance between the points where the variation of the grey value is in the range $20 \%-$ $80 \%$ [73], as required by ISO 18516 [74]. On the other hand, an incorrect method to make the separation of the layers more defined is to digitally postprocessing the images by acting on brightness and contrast. In fact, contrary to varying these parameters during the measurement, by performing software alterations of the image, the edge of the film can move as the different shades of grey are processed, ad demonstrated in Figure 7.

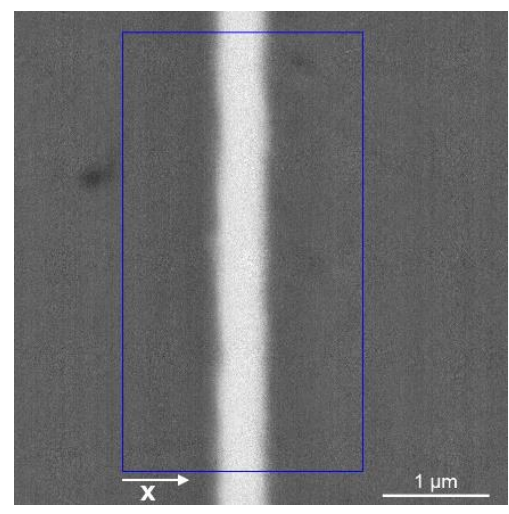

(a)

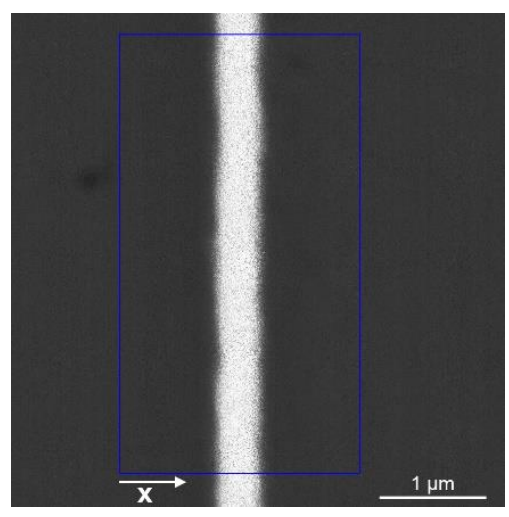

(b)

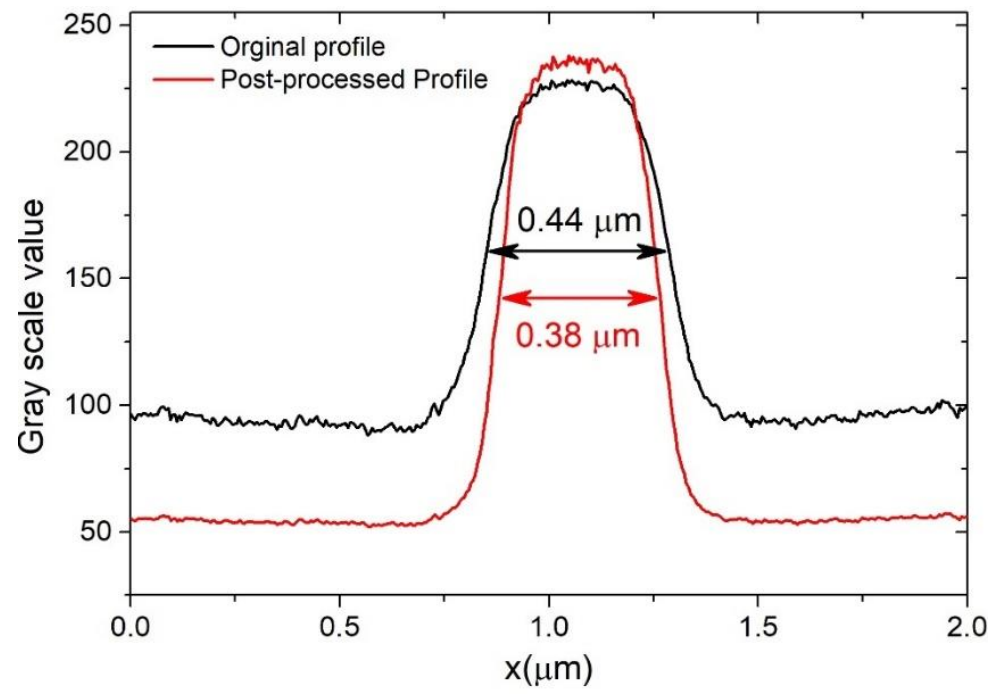

(c)

Figure 7. (a) Au film between two $\mathrm{Cu}$ Layers, picture reported as acquired from the instrument; (b) same picture of (a) but post-processed to enhance the separation between the layers; (c) plot profile of the pictures (a) and (b) and the extrapolated thickness of the Au film.

\section{Non-Destructive Techniques}

\subsection{X-Ray Fluorescence Spectroscopy}

$\mathrm{X}$-ray fluorescence spectroscopy $(\mathrm{XRF})$ is an analysis tool widely used for the elemental analysis and chemical analysis of materials. When materials are exposed to high-energy $\mathrm{X}$-rays, ionization of their component atoms may take place exciting them, during the relaxation process characteristic $X$ photons are emitted and detected for analysis. Due to incident high-energy X-rays the inner shell $(\mathrm{K}$, $\mathrm{L}, \mathrm{M}$, etc.) transition phenomena occurs within $100 \mathrm{fs}$ producing a characteristic fluorescence radiation. Ionization consists of the ejection of one or more electrons from the atom and may occur if 
the atom is exposed to radiation with energy greater than its ionization energy. X-rays and gamma rays can be energetic enough to eject tightly held electrons from the inner orbitals of the atom. The removal of an electron in this way makes the electronic structure of the atom unstable, and electrons in higher orbitals "fall" into the lower orbital to fill the holes left behind. In falling, energy is released in the form of photons with an amount of energy equal to the difference between the two orbitals involved. Thus, materials emit radiations of the characteristic energies of the present atoms. A variety of samples in different states, such as solids, powders, and liquids, can be analysed using this technique. It can also be used to measure the composition, thickness of coating and layers. The characteristic photons of the sample are collected by a detector that uses the same working principle of EPMA. Both the source photons as well the emitted ones could pass through an analysing crystal that act as monochromator differentiating between energy dispersive (ED) XRF without analysing crystal; wavelength dispersive (WD) XRF, in which the emitted photons are selected with a monochromator; monochromatic wavelength dispersive (MWD) XRF, in which two optics are used: one for the source and one for the emitted photons. For reasons of cost and ease of use, energy dispersion instruments are the most used. The incoming high-energy beam is very penetrating Figure 8 , for this reason the maximum detectable thickness is related to the energy to the emitted X-rays.

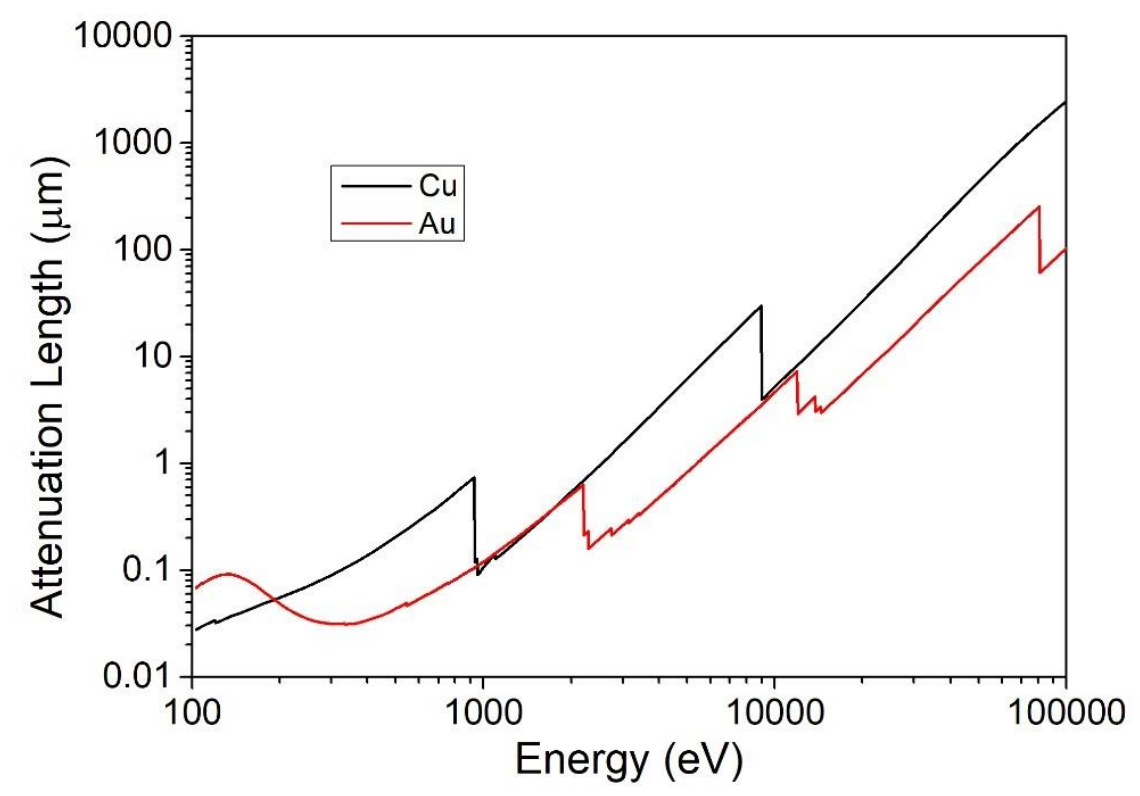

Figure 8. X-ray attenuation length as function of the energy of the photons for copper and gold.

$\mathrm{XRF}$ is the most common instrument used by industries for the film thickness investigation the since it is fast, non-destructive and relatively simple to use, making it perfect for the quality control of the products $[75,76]$, and for this reason there are present also standard procedures to perform the measurement like ISO 3497 [77] and ASTM B568 [78]. Commercial instruments can measure easily the thickness of almost every material (with some restriction for lighter elements), whether conductive or not, in the range from $10 \mathrm{~nm}$ to $100 \mu \mathrm{m}$ [79,80]; nevertheless, depending on the materials under investigation and the instrumental settings, the limits of measurement could be extended from less than $1 \mathrm{~nm}$ [81] to a few centimetres [82]. The lateral resolution of XRF very low and spot size commonly ranges from 0.1 to $15 \mathrm{~mm}$. The relative intensity (normalized respect to bulk element) of an emitted from a film follow an exponential trend [18], but could be approximated to a second order curve for small far from the saturation thickness [7]. The emission of a gold film on $\mathrm{Cu}$ substrate, as function of the thickness, is reported in Figure 9 using a log-log scale. In this case the range of thicknesses between the relative intensities 0.9 (semi-infinite thickness [83]) and 0.1 (infinitely small) gold is between $0.2 \mu \mathrm{m}$ and $50 \mu \mathrm{m}$. 


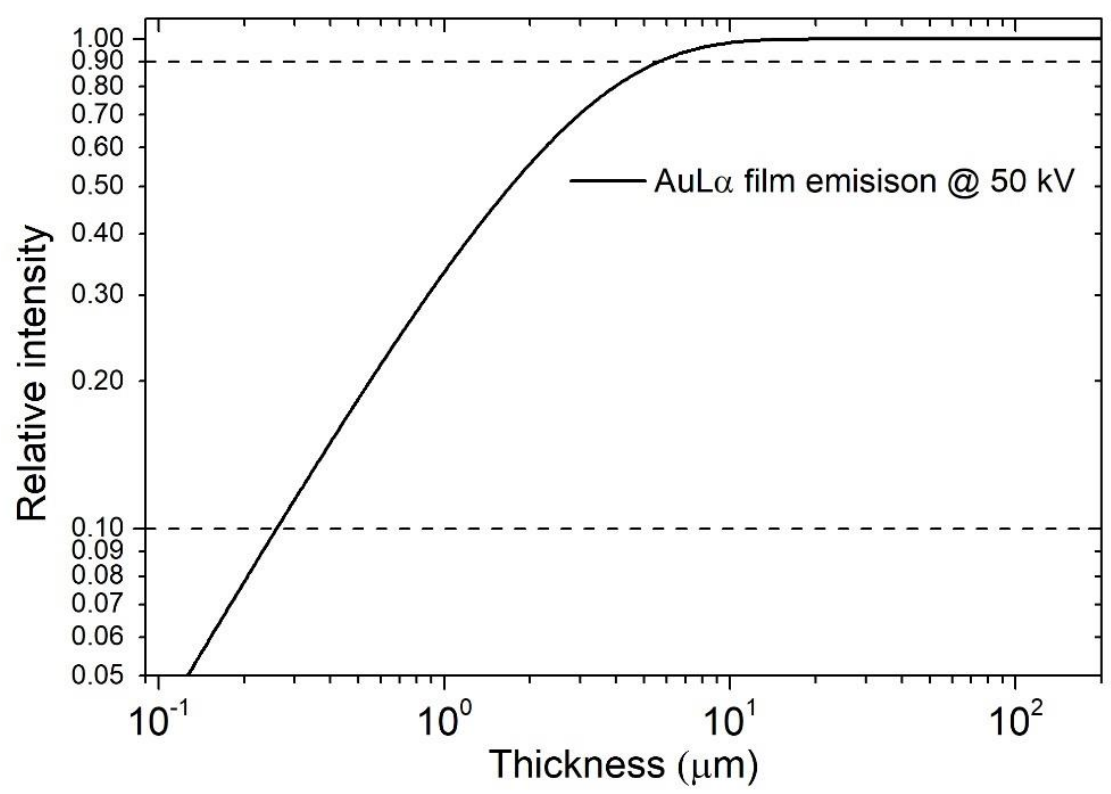

Figure 9. Log-log plot of the emission of $\mathrm{Au}$ film on $\mathrm{Cu}$ as function of the thickness using a $50 \mathrm{kV} \mathrm{X-}$ ray beam. The $10-90 \%$ thickness range is marked.

The output of the instrument is a spectrum in which the position of the peaks corresponds to the spectroscopic emission of the elements present in the sample while the intensity is correlated to the sample composition in the volume of interaction of the incident beam. For this reason, there is no direct information on the thicknesses, but the intensity of the peaks in the spectra will be function of thickness. In fact, a sample with a thicker coating will emit more photons from the film and less from the substrate than a thinner one. Since no information about the thickness can be extracted a priori from the spectra, only with the right assumptions on the nature of the sample and the use of an adequate calibration curve, the thickness information can be deconvoluted: this complication could bring to high uncertainties or even wrong results.

Deriving the coating's thickness from the X-ray spectrum requires an experimental calibration curve that employs standards; however, due to the large dependence of the X-ray spectrum on the nature of the coating and the substrate, standards are not always available. The variability of thickness, layer composition, multilayer architectures and substrate chemical nature create difficulties in producing certified standards. This issue is critical in industrial applications, indeed the determination of precious metal coatings in the fashion industry is a major one where the products are made with many coatings and substrates, with extreme variability in the system. Calibration curve obtained with standards of known thickness was used to measure vanadium $(\mathrm{V})$ oxide nanometric films on glass with portable XRF measuring the attenuation of Ca emission [5]. Hamann [84] was able to detect fraction, up to $1 \%$, of a monolayer of over 20 samples without the use of standards or models, combining WD-XRF and XRD measurement to obtain the proportionality constant between X-ray emitted intensity and the number of atoms per unit area.

Nowadays, the most common approach is the use of the fundamental parameter (FP) method $[6,79,85,86]$. FP relies on theoretical equations that consider the composition and thickness of the sample to evaluate the XRF intensity. Practically, the FP method is combined with a few pure element empirical standards to correct unpredicted deviations due to matrix effects $[87,88]$. With the FP method, it is possible to determine the film thickness of single and even multilayer samples if the structure and the composition are known exactly; nevertheless, the error correlated to the measurement is significant. Typical accuracy for single layer samples is $\pm 5 \%$, while for multiple-layer samples this value grows to $\pm 10 \%$ for the upper layer and $\pm 37 \%$ for the first underlayer [89-91] due to inaccuracy in the method for complex samples. Additionally, very often the thickness and composition of the underlying layers in multilayer architectures are not exactly known and they are introduced in the measurement software using an initial estimation [92]. The FP method was 
investigated by many authors for multi-layered samples in the micron range ( $\mathrm{Au} / \mathrm{Ni} / \mathrm{Cu}$ [89]) as well as in the nanometres range $(\mathrm{Ni} / \mathrm{Cu} / \mathrm{Si}[93])$. This method is very useful when it is difficult to obtain accurate certified reference materials for layer thickness calibration, such as in the case of semiconductor research [94]. Vrilink [90] showed a good correlation between FP and SEM and profilometry measurement of multilayer samples with different composition ( $\mathrm{Rh}, \mathrm{Ta}, \mathrm{W}, \mathrm{Ti}, \mathrm{Pd}, \mathrm{Pt}$, $\mathrm{Ni}, \mathrm{Au}, \mathrm{Cr}$ ) between 20 and $250 \mathrm{~nm}$, considering the density variation for thin film. Ager [92] highlights discrepancy between SEM and non-destructive techniques like RBS and XRF measurement due to differences in density between bulk metal and thin film due to porosity; in the paper comparison between references and electroplated samples were performed to prove the hypothesis for ancient gildings but his considerations are valid in many other fields. Exploiting the FP both the emission line of the top layer as well the reduction in intensity of the underling layer can be used for the thickness determination, as shown in a study of 2017 in which the results of ALD oxides samples are tested [83].

An alternative to the use of standards and FP method, consists in a semiquantitative approaches based on calibration curves obtained with a simulation software using Monte Carlo (MC) algorithms. During the simulation, when the materials and the architecture to simulate are chosen, it is also possible to specify the density of the materials; in this way the user can decide to simulate materials that have a porosity different from the nominal one due to the deposition method, as for example happens during electroplating in which the density of the coatings is often lower than that of the bulk material. Moreover, the MC method simulates X-ray spectra using a statistical approach that counts the photon interactions in the sample. With this approach, inhomogeneities of the sample, spectral and spatial distribution of the beam, polarization effects, photo-absorption, multiple fluorescence, and scattering effects, which are difficult to model with the FP method, can be considered. The simulation approach is not very common, probably because the FP was preferred for many years since it was computationally favourable, but with the last technological development even a personal computer could arrive to obtain a good simulation in relatively small amount of time. The two main software that provide a simulated spectra with MC approach are: XRMC [95] and XMI-MSIM [96]. Both codes use the Xraylib database [97,98]. XRMC is generally used for complex 3D geometries while XMI-MSIM can only simulate samples composed of parallel layers, but for simple geometries XMIMSIM is currently superior to XRMC in simulating XRF experiments [99]. Thickness evaluation using the MC method is diffuse in the field of cultural heritage applications. Schiavon [100] use XRMC code to obtain the thickness and composition of Nuragic manufacts comparing the simulations with the experimental measurements to confirm hypotheses based on bulk chemical composition, structural observations, and historical information. A similar approach was used by Brunetti [101] ad Bottaini [102] for Peruvian and Portuguese manufacts: a MC simulation is performed defining the experimental setup and the sample, then the simulate spectra is compared to the measured one visually and with the chi-squared test. if differences are found, the model is corrected until the two spectra matches determining both the composition and structures. Beside the comparative method MC simulation can be also employed to obtain a calibration curve based on simulated standard. XMIMSIM has been successfully used for this purpose for electroplated samples, normalizing the result respect to semi-infinite bulk element, with even better results than with the FP semi-empirical method [7]. A similar approach was used by Pessanha [8] for cultural heritage gildings on $\mathrm{Pb}$ using PENELOPE code, exploiting the ratio between two lines of the same element for normalization, as if it were an internal standard. This latter method of data processing has been widely used by Cesareo in the last decade [103-108] exploiting the differential attenuation (or self-attenuation) of the substrate (or coating) of two lines of the same element. The curves of the $X$ lines ratios over the thickness can be obtained by knowing the value of this ratios for an infinitely thin layer and a semi-infinite one, these values are tabulated.

$\mathrm{XRF}$ are not commonly used for organic films since they don't give fluorescent radiation detectable in air Porcinai [109] used the X-rays attenuation of the substrate, calculating the ratio between two emission lines of the same element, to evaluate the thickness of polymers for protective purposes; empirical, semi-empirical and analytical (FP) methods were compared. Recently De 
Almeida [110] used a multivariate approach to evaluate multiple regions in the XRF spectra and obtain the thickness of polymeric films. To keep up with all the innovations in this field, every year a review [111-113] on the last advances in XRF group techniques is published to highlights the last developments in instrumentation, methodologies and data handling of this world.

\subsection{Electron Probe Microanalysis}

The electron probe microanalysis (EPMA) was first developed in 1951 by Casting [114]. EPMA permits to analyse the composition of homogeneous materials in a region of few microns from the surface. The EPMA can be conducted using two different approaches: wavelength dispersive X-ray spectroscopy (WDS) [115] or energy dispersive X-ray spectroscopy (EDS) [116-120]. WDS is generally considered an excellent method for microanalysis because is more sensitive and has a higher resolution than EDS but it is more expensive and needs a dedicated device. EDS, on the other hand, can be conducted by simply coupling a detector to SEM, a widespread instrument in the academic and industrial sphere, especially since the recent spread of inexpensive benchtop instrument.

EPMA was mentioned before in the destructive section for mapping the cross-sectioned samples, here it is used as a non-destructive technique measuring the sample perpendicularly to the surface [121]. This technique interprets every sample as homogeneous, since the output information is a spectrum. For this reason, there is no direct information on the thicknesses but the intensity of the peaks in the spectra are function of thickness as well as it is for XRF. EPMA is not much known for thickness measurement but it is an attractive candidate because it enables fast, quantitative [122,123] and non-destructive [124] analysis with the additional benefit of having a lateral resolution in the micron range [125]. In addition to that, the probe (electrons) is not very penetrating (Figure 10) and for this reason it is possible (by adjusting the beam energy) to analyse ultrathin films or just the top layer to obtain its composition [126-130].

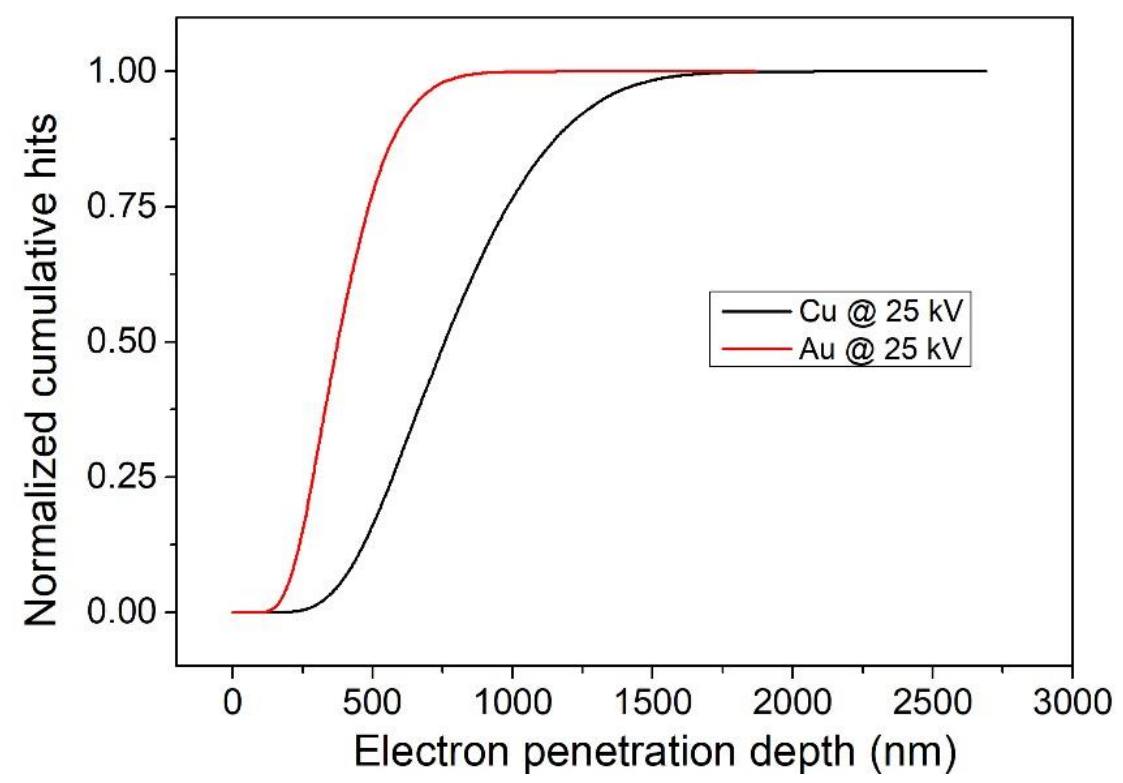

Figure 10. Penetration depth of electrons with an energy of $25 \mathrm{keV}$ in copper and gold.

The EPMA detector is present as an upgrade of conventional SEM, but most of the instruments comes at least with the EDS detector by default. The electron bombardment of the beam excites the atoms in the sample knocking out the electrons from of the inner shells. Such state is unstable, and the resulting electron hole is immediately filled by a higher-energy electron from a higher atomic orbital. The energy difference is released in the form of an X-ray quantum. The resulting X-ray radiation is characteristic of the transition and the atom. For a single element, different transitions are allowed, depending on which shell the higher-energy electron comes from and which shell the hole must be filled in. This results in X-ray quanta, which are marked with $K \alpha, K \beta, L \alpha$, etc. The energy of 
an X-ray lines (position of the lines in the spectrum) is an indicator of which element is under investigation. The intensity of the line depends on the concentration of the element within the sample. Furthermore, the electrons, slowing down in the electric field of the atomic nuclei, generate an X-ray braking radiation, called bremsstrahlung, which constitutes the continuous background of the EPMA spectrum. The EPMA detector exploits the energy interaction between X-rays and a suitable material, generally represented by a silicon single crystal doped with lithium, coated at both ends with a gold conductive layer, at a temperature of $-192{ }^{\circ} \mathrm{C}$ with liquid nitrogen. Other variants are the high purity germanium detectors and silicon drift detector (SSD) with Peltier cooling. When an X-ray photon is absorbed in the sensitive area of the detector, then electron-hole pairs are produced, this cause the production of an electric current, which is then sensitively amplified. In WDS instruments is present a diffracting crystal that select the photons to be send to the detector, which measure only the number of pulses, i.e. photons. In EDS system there is not a photon selector thus the signal of each photon is processed to obtain its energy value; during this time the system reject every other signal resulting in a dead time. High dead time produce high spectra with high resolution but low signal because many photons are rejected, on the other hand low dead time produce high signal but wide peaks. A longer process time is needed for quantitative analysis where spectral resolution is important, whereas if maximizing the number of $\mathrm{X}$-rays in a spectrum or map is most important a shorter process time can be used. $\mathrm{Si}(\mathrm{Li})$ detectors operate at count rates of about 1 to $20 \mathrm{kCPS}$ with optimal dead times of $20-$ $30 \%$. The reason why SDD are now preferred to $\mathrm{Si}(\mathrm{Li})$ detectors is that they can handle much higher count rates of $>100 \mathrm{kCPS}$ and dead times of $50 \%$. The count rate can be optimized by adjusting the beam current (probe current or spot size) and the process time. It is important to select a process time and beam current that will give an acceptable X-ray count rate and detector dead time for analysis, as well as the desired spectral resolution. The typical energy resolution of an EDS detector is $130-$ $140 \mathrm{eV}$ while it is of a about only $10 \mathrm{eV}$ for WDS systems. Moreover, EDS systems have a much lower count rates and poor reproducibility, generally a factor of ten respect to WDS detectors. The Beam energy can be varied to increase sensitivity for thinner of thicker coatings (Figure 11).

The film thickness can be obtained from the measured spectra through various approaches. The calibration curve can be obtained using standards of known thickness [131] or Monte Carlo simulations $[19,20]$. In terms of the quantification method, the quantity used in the calibration curves, multiple alternatives were evaluated: the K-ratio [127,132-134], which is the ratio between the intensity in the sample and the intensity in a standard with known composition, commonly used in que quantification analysis; the ratio of intensities [135] and the atomic ratio [131], obtained performing the ZAF correction algorithm on the K-ratios. Both the absolute thickness [136,137] as well the mass thickness [138-141] was taken into consideration for the quantification.

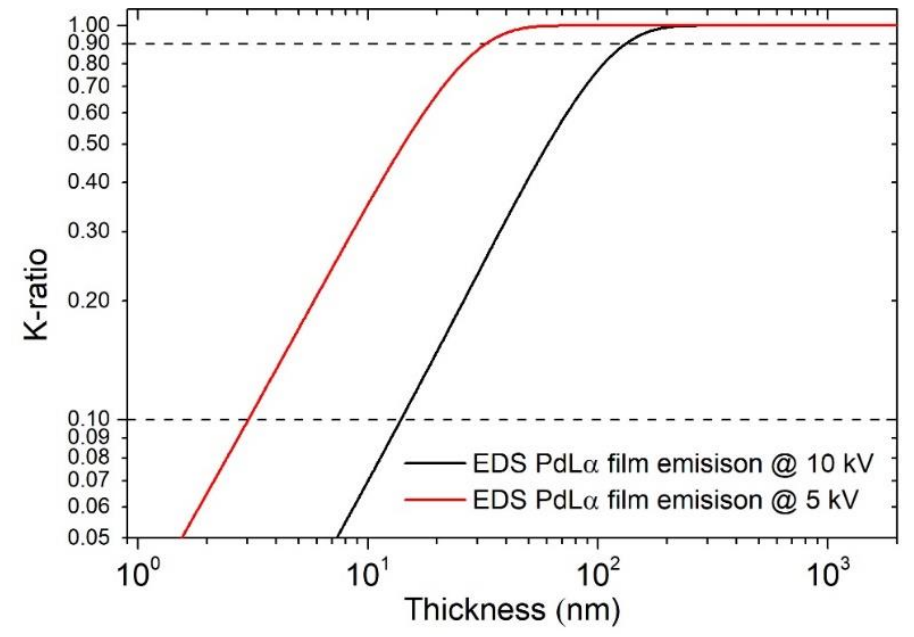

Figure 11. Log-log plot of the emission of $\mathrm{Pd}$ film on $\mathrm{Cu}$ as function of the thickness using a $5 \mathrm{kV}$ and $10 \mathrm{kV}$ electron beam. The $10-90 \%$ thickness range is marked. 
In the last fifty years many software were written to simulate EDS spectra [142]; many of them are written by researcher and some were commercial: MAGIC [143,144], STRATAGEM [145-147], GMRFILM [122], Electron Flight Simulator [148,149], ThinFilmID [150] and LayerProbe [150,151], pyPENELOPE [152,153], Win X-Ray [154,155] and MC X-Ray [154,156], XFilms [157], CASINO [124,158-161], CalcZAF [162,163] and DTSA-II [164-166]. Many of these software exploits the PENEPMA algorithm [153]. PENEPMA is a simplified version dedicated to EPMA, written to perform simulation of $\mathrm{X}$-ray spectra and calculates different quantities of interest, of another algorithm called PENELOPE. PENELOPE (Penetration and ENErgy LOss of Positrons and Electrons) is a general-purpose Monte Carlo code system for the simulation of coupled electron-photon transport in arbitrary materials. PENELOPE covers the energy range from $1 \mathrm{GeV}$ down to, nominally, $50 \mathrm{eV}$. The physical interaction models implemented in the code are based on the most reliable information available at present, limited only by the required generality of the code. These models combine results from first-principles calculations, semi-empirical models and evaluated data bases. It should be borne in mind that although PENELOPE can run particles down to $50 \mathrm{eV}$, the interaction cross sections for energies below $1 \mathrm{keV}$ may be affected by sizeable uncertainties; the results for these energies should be considered as semi-quantitative. PENELOPE incorporates a flexible geometry package called PENGEOM that permits automatic tracking of particles in complex geometries consisting of homogeneous bodies limited by quadratic surfaces. The PENELOPE code system is distributed by the OECD/NEA Data Bank. The distribution package includes a report [167] that provides detailed information on the physical models and random sampling algorithms adopted in PENELOPE, on the PENGEOM geometry package, and on the structure and operation of the simulation routines. PENELOPE is coded as a set of FORTRAN subroutines, which perform the random sampling of interactions and the tracking of particles (either electrons, positrons or photons). In principle, the user should provide a main steering program to follow the particle histories through the material structure and to keep score of quantities of interest. In PENEPMA photon interactions are simulated in chronological succession, allowing the calculation of X-ray fluorescence in complex geometries. PENEPMA makes extensive use of interaction forcing (a variance-reduction technique which artificially increases the probability of occurrence of relevant interactions) to improve the efficiency. CalcZAF [162] simulation software is based on PENEPMA and is a general-purpose software package for simulation of both relativistic and sub relativistic electron interactions with matter. Even in this case, the characteristics and the geometry of the detector are not taken into account and the output consists in a lines-like unconvoluted spectrum. DTSA-II [164] shares many physical models with PENEPMA but was designed exclusively for simulation of X-ray spectra generated by sub relativistic electrons. DTSA2 uses variance reduction techniques unsuited to general purpose code. These optimizations help the program to be orders of magnitude more computationally efficient while retaining the detector position sensitivity. Simulations are executed in minutes rather than hours and differences that result from varying the detector position can be modelled. It is possible to insert the characteristics and the geometry of the detector in DTSA2, which is capable of handling complex sample geometries. The primary and secondary bremsstrahlung and fluorescence can be calculated. The outputs consist in a real-looking spectrum since it is deconvoluted considering the detector resolution; even the electron trajectories can ben visualized. The CASINO [158] is a single scattering Monte Carlo simulation software of electron trajectory in solid specifically designed for low beam interaction in a bulk and thin foil. This software can be used to generate many of the recorded signals (X-rays and backscattered electrons) in a scanning electron microscope. This program can also be efficiently used for all the accelerated voltage found on a field emission scanning electron microscope ( 0.1 to $30 \mathrm{keV}$ ). The characteristics and the geometry of the detector are not taken into account and the output is not a spectrum but the characteristic emission lines intensity as function of the depth.

The X-ray depth distribution of the emissions is described by the $\varphi(\varrho z)$ curve, which can be used for the determination of thin film thicknesses [12]. The thickness of the film can vary between two extremes relatively to the curve: extremely thin or extremely thick [137]. In the first case, the emission corresponds to a bulk sample with the composition of the substrate, in the second case, to a bulk with 
the composition of the film. In the intermediate cases the $\varphi(\mathrm{gz})$ curves vary between these two extremes. The maximum thickness that can be analysed with the EPMA method is about some microns: this is determined by the acceleration potential of the electrons together with the atomic number of the elements in the sample [168]. On the other hand, the minimum detectable thickness (lower detection limit) is given by the combination of the X-ray energy characteristics of the elements in the sample and the properties of the detector and can be as low as a few monolayer or less [169].

Exploiting STRATAGEM software Kühn [146] was capable to obtain both the elemental composition and thickness of a thin film ternary alloy Pd-Ni-Co co-deposited via magnetron sputtering on silicon wafer by ED-EPMA in the range of 50 to $250 \mathrm{~nm}$. The results were confirmed by AES and XPS measurement, for the composition, and by SEM imaging for the thickness. The volume of interanion was confirmed by CASINO simulations. A similar approach was used for the determination of electrodeposited $\mathrm{Ni}, \mathrm{Pd}$ and $\mathrm{Au}$ on $\mathrm{Cu}$ comparing the results of CASINO, CalcZAF and DTSA [18]. A comparation between GRMfilm, DTSA-II and PENEPMA was performed for very thin films $(5-20 \mathrm{~m})$ of $\mathrm{Al}$ an $\mathrm{Cu}$ on $\mathrm{Bi}$, in this study also the variation in the film density respect to the bulk material was evaluated [170]. Ultra-thin film of Ge, Sn, Ag and Au on Si wafer was evaluated also by Campos performing multiple analysis with different beam energy [171]. DTSA-II was used also to determine the sputter coater deposition of $\mathrm{Ti}$ and Ag on Si for medical applications [172]. Osada [136] developed it's a new MC simulation software to evaluate the thickness of aluminium oxide on aluminium sheets in in the range $5 \mathrm{~nm}$ to $50 \mathrm{~nm}$. Recently, in 2018, Darznek Performed thickness measurement tilting the sample off to the normal incidence angle to increase the signal of the superficial coatings, specifically to determine the thickness of chromium film on a silicon substrate. With this approach he was able to determine up to $10^{14}$ atoms per square centimetre with an error less than $10 \%$ exploiting K-ratio measurement with MC simulation.

In 2016 Sokolov [124] measured the thickness of Silicon dioxide and silicon nitride thin films using EDS varying the penetration depth of the analysis changing the acceleration voltage of the beam and correlating the thickness of the film with the signal of the substrate elements to the collected noise. Stanford [173] in 2020 measured the oxide layer formation on Pu from $35 \mathrm{~nm}$ to $400 \mathrm{~nm}$ using measured standards to build the k-ratio calibration curves of oxygen through FIM-SEM analysis. Previously Bastin made a massive work collecting the K-ratio of $\mathrm{Al}$ [174] and Pd [175] of films from 10 to $320 \mathrm{~nm}$ in thickness at various beam energies between $3 \mathrm{kV}$ and $30 \mathrm{kV}$ on many substrates between Be and Bi.

Even the thickness of multi-layered samples can be measured using EPMA measurements [176,177]. In 2019 Pazzaglia [178] developed a new model for the standardless determination of mass thickness and composition using EDS for multilayer samples with an accuracy of $10 \mu \mathrm{g} / \mathrm{cm}^{2}$. Previously Lesch used a sputtering method with EPMA, the signal deconvolution with max entropy algorithm provide the thickness of $\mathrm{Ti} / \mathrm{Al} / \mathrm{Ti}$ layers deposited on $\mathrm{Si}$.

EPMA was used by some authors to evaluate important information about layered samples besides their thickness: Christien [119] used the EDS measurement to determine the interdiffusion coefficient between thin films of miscible metals. Using various annealing temperature and the Fick's diffusion equations he was able to estimate the coefficients for a Ni film on Pd. Darznek [179] proposed a method to evaluate thickness uniformity of nanofilms by means MC simulations correlating the peaks intensities in the EDS spectrum to the film thickness. In 2016 Ortel [116] developed a technique combining EPMA measurement for mass deposition determination and SEM analysis for thickness determination to obtain the change in density of the films respect to the bulk materials and consequently extrapolate the porosity of the coatings.

\section{Conclusions}

Thickness measurement is a challenge that affects many scientists and companies. The composite materials on which a coating is present are ubiquitous and allow to obtain properties that a single element would not have. Thickness is decisive for obtaining these properties, and thus its control and measurement. In this review we describe the main techniques, both of preparation and analysis, which are used both in research and in the industrial sector for this purpose. In fact, there is 
no perfect technique suitable for any type of sample, but the most appropriate route must be chosen for every need. At the end of this work, it seems appropriate to report a roughly comparison between the various methods as regards the range of thicknesses that can be analyzed (Figure 12) and the times required to carry out the analysis (Figure 13). Obviously, the costs are also an important parameter to consider and they are very variable: from a general point of view mechanical and optical techniques are cheaper than the electronic, ionic and spectroscopic ones. It should also be taken into account that some instruments are supplied with multiple combined analyzers such as in the case of SE, BSE and EDS or for FIB techniques.

Talking about the measurable ranges of thickness, microscopic techniques tend to have only a lower limit, dictated by the aberrations that the beam undergoes under certain dimensions, while it is possible to lower the magnifications until observing shapes above the millimeter. Spectroscopic techniques instead suffer from the attenuation of the signal inside the sample and therefore cannot measure coatings beyond a certain size which appear as infinitely thick. Furthermore, for those analysis techniques that require sample preparation, the range that can be analyzed is the intersection of the ranges of the individual techniques.

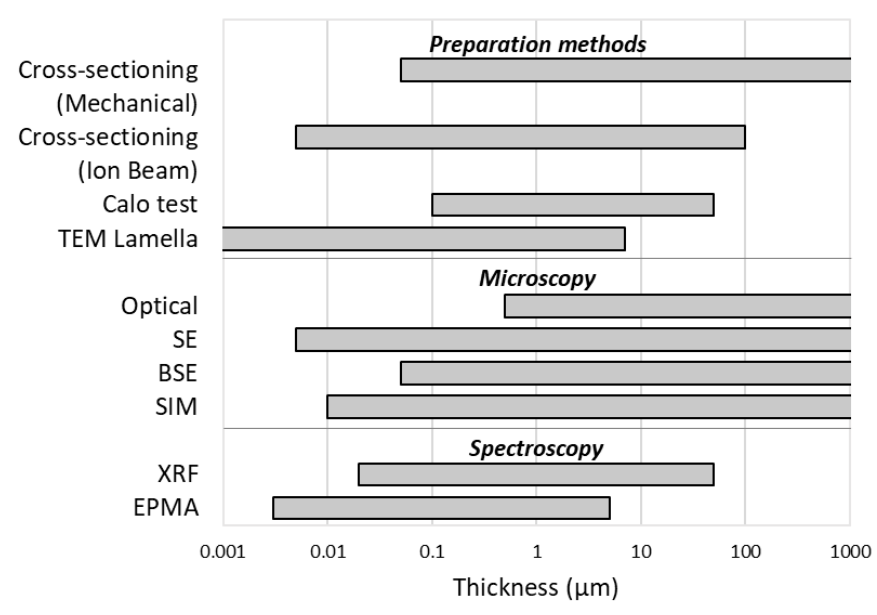

Figure 12. Range of thicknesses that a metal sample must have to be properly analyzed for each technique.

Considering now the preparation and measurement time, it is highly dependent on the presence of automated systems and on the experience and manual skills of the operator, as well as on the degree of accuracy required for the result. In general, the XRF, in addition to being extremely versatile, is the fastest technique, not even requiring sample preparation. On the other hand, microscopic techniques coupled to cross-sectioning are extremely widespread as they allow to obtain a result in which the thickness is directly visible. Furthermore, cross sectioning, although being time consuming, is a procedure that is generally automated. 


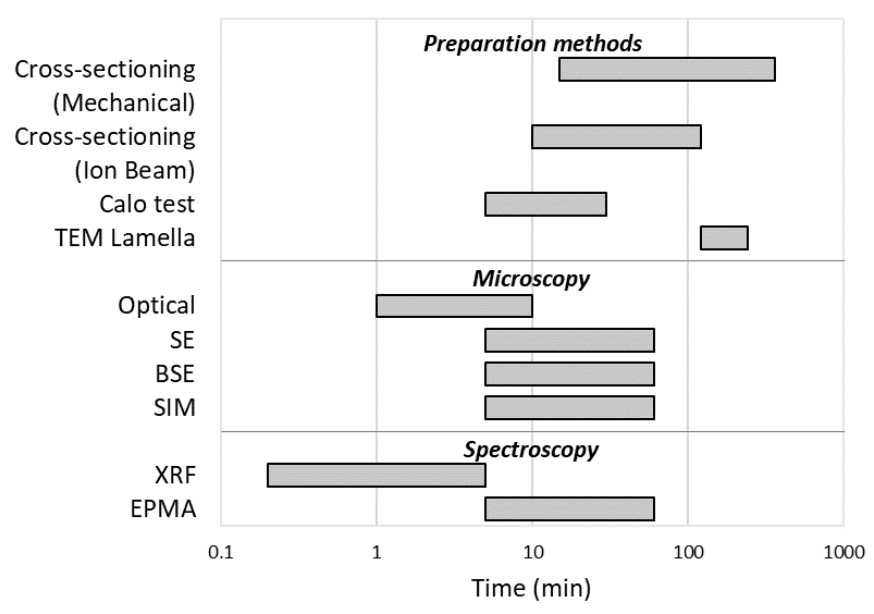

Figure 13. Time needed for the measurement and preparation of a sample for each technique.

Some of the illustrated techniques are well established and have not undergone many innovations in recent years, if not an engineering optimization of performance and costs; for others however, research is still very active, as we have shown in this work, therefore they must be followed with interest in order to make the best use of them as a powerful analytical tool as they are.

Author Contributions: writing-original draft preparation, W.G. and E.B; writing-review and editing, W.G. and E.B.; supervision, A.L. and M.I.; project administration, A.L. and M.I.; funding acquisition, A.L. and M.I.

Funding: This research was funded by the PRIN ("Progetti di Ricerca di Rilevante Interesse Nazionale"), which made possible the project "Novel Multilayered and Micro-Machined Electrode Nano-Architectures for Electrocatalytic Applications (Fuel Cells and Electrolyzers)", grant number 2017YH9MRK. The authors also acknowledge "Ente Cassa di Risparmio di Firenze" Grant Number n. 2013.0878, Regione Toscana POR FESR 2014-2020 for the project FELIX (Fotonica ed Elettronica Integrate per l'Industria), Grant Number 6455.

Conflicts of Interest: The authors declare no conflict of interest.

\section{References}

1. Whiteside, P.; Chininis, J.; Hunt, H. Techniques and Challenges for Characterizing Metal Thin Films with Applications in Photonics. Coatings 2016, 6, 35, doi:10.3390/coatings6030035.

2. Nash, C. R.; Fenton, J. C.; Constantino, N. G. N.; Warburton, P. A. Compact chromium oxide thin film resistors for use in nanoscale quantum circuits. J. Appl. Phys. 2014, 116, doi:10.1063/1.4901933.

3. Lobo, R. F. M.; Pereira-da-Silva, M. A.; Raposo, M.; Faria, R. M.; Oliveira, O. N. In situ thickness measurements of ultra-thin multilayer polymer films by atomic force microscopy. Nanotechnology 1999, 10, 389-393, doi:10.1088/0957-4484/10/4/305.

4. Sitko, R. Quantitative X-ray fluorescence analysis of samples of less than "infinite thickness": Difficulties and possibilities. Spectrochim. Acta - Part B At. Spectrosc. 2009, 64, 1161-1172, doi:10.1016/j.sab.2009.09.005.

5. Lopes, F.; Cardozo Amorin, L. H.; da Silva Martins, L.; Urbano, A.; Roberto Appoloni, C.; Cesareo, R. Thickness Measurement of V2O5 Nanometric Thin Films Using a Portable XRF. J. Spectrosc. 2016, 2016, 17, doi:10.1155/2016/9509043.

6. Criss, J. W.; Birks, L. S. Calculation Methods for Fluorescent X-Ray Spectrometry: Empirical Coefficients vs. Fundamental Parameters. Anal. Chem. 1968, 40, 1080-1086, doi:10.1021/ac60263a023.

7. Giurlani, W.; Berretti, E.; Innocenti, M.; Lavacchi, A. Coating Thickness Determination Using X-ray Fluorescence Spectroscopy: Monte Carlo Simulations as an Alternative to the Use of Standards. Coatings 2019, 9, 79, doi:10.3390/coatings9020079.

8. Pessanha, S.; Manso, M.; Antunes, V.; Carvalho, M. L.; Sampaio, J. M. Monte Carlo simulation of portable X-ray fluorescence setup: Non-invasive determination of gold leaf thickness in indo-Portuguese panel paintings. Spectrochim. Acta Part B At. Spectrosc. 2019, 156, 1-6, doi:10.1016/j.sab.2019.04.006. 
9. Malarde, D.; Powell, M. J.; Quesada-Cabrera, R.; Wilson, R. L.; Carmalt, C. J.; Sankar, G.; Parkin, I. P.; Palgrave, R. G. Optimized Atmospheric-Pressure Chemical Vapor Deposition Thermochromic VO2 Thin Films for Intelligent Window Applications. ACS Omega 2017, 2, 1040-1046, doi:10.1021/acsomega.7b00042.

10. Krumrey, M.; Gleber, G.; Scholze, F.; Wernecke, J. Synchrotron radiation-based x-ray reflection and scattering techniques for dimensional nanometrology. Meas. Sci. Technol. 2011, 22, doi:10.1088/09570233/22/9/094032.

11. Serafińczuk, J.; Pietrucha, J.; Schroeder, G.; Gotszalk, T. P. Thin film thickness determination using X-ray reflectivity and Savitzky-Golay algorithm. Opt. Appl. 2011, 41, 315-322.

12. Sokolov, S. A.; Milovanov, R. A.; Sidorov, L. N. Determination of the Thickness of Thin Films Based on Scanning Electron Microscopy and Energy Dispersive X-Ray Analysis. J. Surf. Investig. X-ray, Synchrotron Neutron Tech. 2019, 13, 836-847, doi:10.1134/S1027451019050136.

13. Goldstein, J. I.; Newbury, D. E.; Michael, J. R.; Ritchie, N. W. M.; Scott, J. H. J.; Joy, D. C. Scanning Electron Microscopy and X-Ray Microanalysis; Springer Publishing: New York City, 2018; ISBN 978-1-4939-6674-5.

14. Jablonski, A. Evaluation of procedures for overlayer thickness determination from XPS intensities. Surf. Sci. 2019, 688, 14-24, doi:10.1016/j.susc.2019.05.004.

15. Walton, J.; Alexander, M. R.; Fairley, N.; Roach, P.; Shard, A. G. Film thickness measurement and contamination layer correction for quantitative XPS. Surf. Interface Anal. 2016, 48, 164-172, doi:10.1002/sia.5934.

16. Cumpson, P. J. The Thickogram: a method for easy film thickness measurement in XPS. Surf. Interface Anal. 2000, 29, 403-406, doi:10.1002/1096-9918(200006)29:6<403::AID-SIA884>3.0.CO;2-8.

17. Alexander, M. R.; Thompson, G. E.; Zhou, X.; Beamson, G.; Fairley, N. Quantification of oxide film thickness at the surface of aluminium using XPS. Surf. Interface Anal. 2002, 34, 485-489, doi:10.1002/sia.1344.

18. Giurlani, W.; Innocenti, M.; Lavacchi, A. X-ray Microanalysis of Precious Metal Thin Films: Thickness and Composition Determination. Coatings 2018, 8, 84, doi:10.3390/coatings8020084.

19. Kyser, D. F.; Murata, K. Quantitative Electron Microprobe Analysis of Thin Films on Substrates. IBM J. RES. Dev. 1974, 92, 352-363, doi:10.1147/rd.184.0352.

20. Roming AD, Plimpton SJ, Michael JR, Myklebust RL, N. DE Microbeam Analysis; 1990;

21. Hill, J. M.; Royce, D. G.; Fadley, C. S.; Wagner, L. F.; Grunthaner, F. J. Properties of oxidized silicon as determined by angular-dependent X-ray photoelectron spectroscopy. Chem. Phys. Lett. 1976, 44, 225-231, doi:10.1016/0009-2614(76)80496-4.

22. Benoit, M.; Bataillon, C.; Gwinner, B.; Miserque, F.; Orazem, M. E.; Sánchez-Sánchez, C. M.; Tribollet, B.; Vivier, V. Comparison of different methods for measuring the passive film thickness on metals. Electrochim. Acta 2016, 201, 340-347, doi:10.1016/j.electacta.2015.12.173.

23. Passiu, C.; Rossi, A.; Weinert, M.; Tysoe, W.; Spencer, N. D. Probing the outermost layer of thin gold films by XPS and density functional theory. Appl. Surf. Sci. 2020, 507, 145084, doi:10.1016/j.apsusc.2019.145084.

24. Tougaard, S. Surface nanostructure determination by x-ray photoemission spectroscopy peak shape analysis. J. Vac. Sci. Technol. A Vacuum, Surfaces, Film. 1996, 14, 1415-1423, doi:10.1116/1.579963.

25. Matthew, J. Surface analysis by Auger and x-ray photoelectron spectroscopy. D. Briggs and J. T. Grant (eds). IMPublications, Chichester, UK and SurfaceSpectra, Manchester, UK, 2003. 900 pp., ISBN 1-90101904-7, 900 pp. Surf. Interface Anal. 2004, 36, 1647-1647, doi:10.1002/sia.2005.

26. Elsener, B.; Rossi, A. XPS investigation of passive films on amorphous Fe Cr alloys. Electrochim. Acta 1992, 37, 2269-2276, doi:10.1016/0013-4686(92)85122-2.

27. Rossi, A.; Elsener, B. XPS analysis of passive films on the amorphous alloy Fe70Cr10P13C7: Effect of the applied potential. Surf. Interface Anal. 1992, 18, 499-504, doi:10.1002/sia.740180708.

28. Asami, K.; Hashimoto, K. An XPS study of the surfaces on Fe-Cr, Fe-Co and Fe-Ni alloys after mechanical polishing. Corros. Sci. 1984, 24, 83-97, doi:10.1016/0010-938X(84)90039-8.

29. Jeynes, C.; Colaux, J. L. Thin film depth profiling by ion beam analysis. Analyst 2016, 141, 5944-5985, doi:10.1039/C6AN01167E.

30. Ho, S. M. Investigation of the electrical properties of metal chalcogenide thin films: A review. Der Pharma Chem. 2016, 8, 17-20.

31. Hofmann, S.; Zhou, G.; Kovac, J.; Drev, S.; Lian, S. Y.; Lin, B.; Liu, Y.; Wang, J. Y. Preferential sputtering effects in depth profiling of multilayers with SIMS, XPS and AES. Appl. Surf. Sci. 2019, 483, 140-155, doi:10.1016/j.apsusc.2019.03.211. 
32. Bardi, U.; Caporali, S.; Chenakin, S. P.; Lavacchi, A.; Miorin, E.; Pagura, C.; Tolstogouzov, A. Characterization of electrodeposited metal coatings by secondary ion mass spectrometry. Surf. Coatings Technol. 2006, 200, 2870-2874, doi:10.1016/j.surfcoat.2004.11.029.

33. Bardi, U.; Chenakin, S. P.; Ghezzi, F.; Giolli, C.; Goruppa, A.; Lavacchi, A.; Miorin, E.; Pagura, C.; Tolstogouzov, A. High-temperature oxidation of CrN/AlN multilayer coatings. Appl. Surf. Sci. 2005, 252, 1339-1349, doi:10.1016/j.apsusc.2005.02.105.

34. Kalina, L.; Bílek Jr., V.; Bušo, M.; Koplík, J.; Másilko, J. Thickness determination of corrosion layers on iron using XPS depth profiling. Mater. Tehnol. 2018, 52, 537-540, doi:10.17222/mit.2016.180.

35. Scorciapino, M. A.; Navarra, G.; Elsener, B.; Rossi, A. Nondestructive Surface Depth Profiles from AngleResolved X-ray Photoelectron Spectroscopy Data Using the Maximum Entropy Method. I. A New Protocol. J. Phys. Chem. C 2009, 113, 21328-21337, doi:10.1021/jp906326m.

36. Olla, M.; Navarra, G.; Elsener, B.; Rossi, A. Nondestructive in-depth composition profile of oxy-hydroxide nanolayers on iron surfaces from ARXPS measurement. Surf. Interface Anal. 2006, 38, 964-974, doi:10.1002/sia.2362.

37. Smith, G. C.; Livesey, A. K. Maximum entropy: A new approach to non-destructive deconvolution of depth profiles from angle-dependent XPS. Surf. Interface Anal. 1992, 19, 175-180, doi:10.1002/sia.740190134.

38. Skilling, J.; Bryan, R. K. Maximum entropy image reconstruction: general algorithm. Mon. Not. R. Astron. Soc. 1984, 211, 111-124, doi:10.1093/mnras/211.1.111.

39. Ishitani, T.; Yaguchi, T. Cross-sectional sample preparation by focused ion beam: A review of ion-sample interaction. Microsc. Res. Tech. 1996, 35, 320-333, doi:10.1002/(SICI)1097-0029(19961101)35:4<320::AIDJEMT3>3.0.CO;2-Q.

40. Mohamad Rashid, N. N.; Ahmad Junaidi, N. H.; Rahmah Aid, S. Interface Damage of Protective Layer in TEM Lamella Preparation for Highly Doped Ge Substrate. IOP Conf. Ser. Mater. Sci. Eng. 2019, 522, 012003, doi:10.1088/1757-899X/522/1/012003.

41. Khamsehpour, B.; Davies, S. T. Angle lapping of multilayer structures for thickness measurements using focused ion beam micromachining. Semicond. Sci. Technol. 1994, 9, 249-255, doi:10.1088/0268-1242/9/3/003.

42. Gao, S.; Kang, R. K.; Guo, D. M.; Huang, Q. S. Study on the subsurface damage distribution of the silicon wafer ground by diamond wheel. Adv. Mater. Res. 2010, 126-128, 113-118, doi:10.4028/www.scientific.net/AMR.126-128.113.

43. Mayer, J.; Giannuzzi, L. A.; Kamino, T.; Michael, J. TEM sample preparation and FIB-induced damage. MRS Bull. 2007, 32, 400-407, doi:10.1557/mrs2007.63.

44. Schaffer, M.; Schaffer, B.; Ramasse, Q. Sample preparation for atomic-resolution STEM at low voltages by FIB. Ultramicroscopy 2012, 114, 62-71, doi:10.1016/j.ultramic.2012.01.005.

45. ISO 26423:2009 Fine ceramics (advanced ceramics, advanced technical ceramics) - Determination of coating thickness by crater-grinding method. 2009.

46. Vidakis, N.; Antoniadis, A.; Bilalis, N. The VDI 3198 indentation test evaluation of a reliable qualitative control for layered compounds. J. Mater. Process. Technol. 2003, 143-144, 481-485, doi:10.1016/S09240136(03)00300-5.

47. Randall, N. Finer particle size allows better coating characterization with the Calotest. Appl. Bull. 1997, 36.

48. Demas, N. G.; Lorenzo-Martin, C.; Ajayi, O. O.; Erck, R. A.; Shareef, I. Measurement of Thin-film Coating Hardness in the Presence of Contamination and Roughness: Implications for Tribology. Metall. Mater. Trans. A Phys. Metall. Mater. Sci. 2016, 47, 1629-1640, doi:10.1007/s11661-016-3342-9.

49. Rupetsov, V.; Minchev, R. Experimental Calo Tester for the Coating Thickness Measurement. XV Int. Sci. Conf. 2016, 188-192.

50. Özkan, D.; Kaleli, H.; Yüksek, L. Quantitative comparison of tribological performance of chromium- and zinc-phosphate-coated piston rings in tribotest rig. Proc. Inst. Mech. Eng. Part J J. Eng. Tribol. 2017, 231, 75-92, doi:10.1177/1350650116646918.

51. Škarohlíd, J.; Ashcheulov, P.; Škoda, R.; Taylor, A.; Čtvrtlík, R.; Tomáštík, J.; Fendrych, F.; Kopeček, J.; Cháb, V.; Cichoň, S.; Sajdl, P.; Macák, J.; Xu, P.; Partezana, J. M.; Lorinč́́k, J.; Prehradná, J.; Steinbrück, M.; Kratochvílová, I. Nanocrystalline diamond protects Zr cladding surface against oxygen and hydrogen uptake: Nuclear fuel durability enhancement. Sci. Rep. 2017, 7, 6469, doi:10.1038/s41598-017-06923-4. 
52. Vieira Junior, L. E.; Bendo, T.; Nieto, M. I.; Klein, A. N.; Hotza, D.; Moreno, R.; Rodrigues Neto, J. B. Processing of Copper Based Foil Hardened with Zirconia by Non-Deformation Method. Mater. Res. 2017, 20, 835-842, doi:10.1590/1980-5373-mr-2016-0574.

53. Nyyssonen, D.; Kirk, C. P. Optical microscope imaging of lines patterned in thick layers with variable edge geometry: theory. J. Opt. Soc. Am. A 1988, 5, 1270, doi:10.1364/JOSAA.5.001270.

54. Sakai, Y.; Yamada, T.; Suzuki, T.; Ichinokawa, T. Contrast mechanisms of secondary electron images in scanning electron and ion microscopy. Appl. Surf. Sci. 1999, 144-145, 96-100, doi:10.1016/S01694332(98)00773-9.

55. Li, P.; Bao, S. X.; Zhang, D. Z.; Zhuang, L. B.; Ma, L. L. Application of Secondary Electron Composition Contrast Imaging Method in Microstructure Studies on Cathode Materials of TWT. Mater. Sci. Forum 2011, 689, 255-259, doi:10.4028/www.scientific.net/MSF.689.255.

56. Sohail, K.; Khan, I. U.; Shahzad, Y.; Hussain, T.; Ranjha, N. M. Ph-sensitive polyvinylpyrrolidone-acrylic acid hydrogels: Impact of material parameters on swelling and drug release. Brazilian J. Pharm. Sci. 2014, 50, 173-184, doi:10.1590/S1984-82502011000100018.

57. Gierak, J. Focused ion beam technology and ultimate applications. Semicond. Sci. Technol. 2009, 24, doi:10.1088/0268-1242/24/4/043001.

58. Kleyn, A. W. Ion-Surface Interactions--From Channeling to Soft-Landing. Science (80-. ). 1997, 275, 14401441, doi:10.1126/science.275.5305.1440.

59. Huh, Y.; Hong, K. J.; Shin, K. S. Amorphization Induced by Focused Ion Beam Milling in Metallic and Electronic Materials. Microsc. Microanal. 2013, 19, 33-37, doi:10.1017/S1431927613012282.

60. Williams, J. S. Ion Implantation and Beam Processing; Elsevier, 1984; ISBN 9780127569802.

61. MoberlyChan, W. J.; Adams, D. P.; Aziz, M. J.; Hobler, G.; Schenkel, T. Fundamentals of focused ion beam nanostructural processing: Below, at, and above the surface. MRS Bull. 2007, 32, 424-432, doi:10.1557/mrs2007.66.

62. Ishitani, T.; Tsuboi, H. Objective comparison of scanning ion and scanning electron microscope images. Scanning 1997, 19, 489-497, doi:10.1002/sca.4950190707.

63. Tseng, A. A. Recent developments in micromilling using focused ion beam technology. J. Micromechanics Microengineering 2004, 14, doi:10.1088/0960-1317/14/4/R01.

64. van Kouwen, L. Introduction to focused ion beams, ion sources, and the nano-aperture ion source. In; 2019; pp. 181-216.

65. Joy, D. C. SEM for the 21st century-scanning ion microscopy. Electron. Device Fail. Anal. 2012, 14, 4-12, doi:10.1007/s13632-012-0013-0.

66. Eder, K.; Bhatia, V.; Van Leer, B.; Cairney, J. M. Using a Plasma FIB Equipped with Xe, N 2 , O 2 and Ar for Atom Probe Sample Preparation - Ion Implantation and Success Rates. Microsc. Microanal. 2019, 25, 316317, doi:10.1017/S1431927619002319.

67. Ernst, A.; Wei, M.; Aindow, M. A Comparison of Ga FIB and Xe-Plasma FIB of Complex Al Alloys. Microsc. Microanal. 2017, 23, 288-289, doi:10.1017/s1431927617002124.

68. Kant, K.; Losic, D. FIB Nanostructures. 2013, 20, 1-22, doi:10.1007/978-3-319-02874-3.

69. An, B.-S.; Kwon, Y.; Oh, J.-S.; Shin, Y.-J.; Ju, J.; Yang, C.-W. Evaluation of ion/electron beam induced deposition for electrical connection using a modern focused ion beam system. Appl. Microsc. 2019, 49, doi:10.1186/s42649-019-0008-2.

70. Tan, S.; Livengood, R.; Shima, D.; Notte, J.; McVey, S. Gas field ion source and liquid metal ion source charged particle material interaction study for semiconductor nanomachining applications. J. Vac. Sci. Technol. B, Nanotechnol. Microelectron. Mater. Process. Meas. Phenom. 2010, 28, C6F15-C6F21, doi:10.1116/1.3511509.

71. Scipioni, L.; Stern, L. A.; Notte, J.; Sijbrandij, S.; Griffin, B. Helium ion microscope. Adv. Mater. Process. 2008, 166, 27-30, doi:10.1116/1.4863676.

72. Giannuzzi, L. A.; Michael, J. R. Comparison of channeling contrast between ion and electron images. Microsc. Microanal. 2013, 19, 344-349, doi:10.1017/S1431927612014286.

73. Passiu, C.; Rossi, A.; Bernard, L.; Paul, D.; Hammond, J.; Unger, W. E. S.; Venkataraman, N. V.; Spencer, N. D. Fabrication and Microscopic and Spectroscopic Characterization of Planar, Bimetallic, Micro- and Nanopatterned Surfaces. Langmuir 2017, 33, 5657-5665, doi:10.1021/acs.langmuir.7b00942. 
74. ISO 18516 - Surface chemical analysis - Auger electron spectroscopy and X-ray photoelectron spectroscopy Determination of lateral resolution; International Organization for Standardization: Geneva, Switzerland, 2006;

75. Giurlani, W.; Zangari, G.; Gambinossi, F.; Passaponti, M.; Salvietti, E.; Di Benedetto, F.; Caporali, S.; Innocenti, M. Electroplating for Decorative Applications: Recent Trends in Research and Development. Coatings 2018, 8, 260, doi:10.3390/coatings8080260.

76. Innocenti, M.; Giurlani, W.; Passaponti, M.; Luca, D.; Salvietti, E. Electrodeposition and innovative characterization of precious metal alloys for the Galvanic and Jewel industry. Substantia 2019, 3, 29-37, doi:10.13128/Substantia-602.

77. ISO 3497:2000 Metallic Coatings - Measurement of Coating Thickness - X-ray Spectrometric Methods; International Organization for Standardization: Geneva, Switzerland, 2000;

78. ASTM B568-98 Standard Test Method for Measurement of Coating Thickness by X-Ray Spectrometry; International ASTM, 1998;

79. Takahara, H. Thickness and composition analysis of thin film samples using FP method by XRF analysis; $2017 ; \mathrm{Vol}$. 33;.

80. Boehm, S.; Bügler, M. J. L. Layer Thickness Analysis of Thin Metal Coatings with micro-XRF on SEM. In Bruker Nano Analytics, Berlin, Germany; 2017.

81. AXIC, I. Non-Destructive Composition and Thickness Analysis of Metal Films Using Combination EDS/WDS XRay Fluorescence Spectrometry;

82. Brouwer, P. Theory of XRF - Getting acquainted with the principles; 2010; ISBN 9090167587.

83. Abdel-Fattah, T. M.; Wixtrom, A.; Arias, L.; Zhang, K.; Baumgart, H. Quantitative Analysis of X-ray Fluorescence Absorption and Emission for Thickness Determination of ALD-Grown Metal and Oxide Nanoscaled Films. J. Nanosci. Nanotechnol. 2017, 17, 5745-5750, doi:10.1166/jnn.2017.13827.

84. Hamann, D. M.; Bardgett, D.; Cordova, D. L. M.; Maynard, L. A.; Hadland, E. C.; Lygo, A. C.; Wood, S. R.; Esters, M.; Johnson, D. C. Sub-Monolayer Accuracy in Determining the Number of Atoms per Unit Area in Ultrathin Films Using X-ray Fluorescence. Chem. Mater. 2018, 30, 6209-6216, doi:10.1021/acs.chemmater.8b02591.

85. Kataoka, Y. Standardless x-ray fluorescence spectrometry (Fundamental Parameter Method using Sensitivity Library). Rigaku J. 1989, 6, 33-40.

86. Thomsen, V. Basic Fundamental Parameters in X-Ray Fluorescence. Spectroscopy 2007, 22, 46-50.

87. Han, X. Y.; Zhuo, S. J.; Shen, R. X.; Wang, P. L.; Ji, A. Comparison of the quantitative results corrected by fundamental parameter method and difference calibration specimens in X-ray fluorescence spectrometry. J. Quant. Spectrosc. Radiat. Transf. 2006, 97, 68-74, doi:10.1016/j.jqsrt.2004.12.018.

88. Pessanha, S.; Fonseca, C.; Santos, J. P.; Carvalho, M. L.; Dias, A. A. Comparison of standard-based and standardless methods of quantification used in X-ray fluorescence analysis: Application to the exoskeleton of clams. X-Ray Spectrom. 2018, 47, 108-115, doi:10.1002/xrs.2819.

89. Nygård, K.; Hämäläinen, K.; Manninen, S.; Jalas, P.; Ruottinen, J.-P. Quantitative thickness determination using x-ray fluorescence: application to multiple layers. X-Ray Spectrom. 2004, 33, 354-359, doi:10.1002/xrs.729.

90. Vrielink, J. A. M. A. M.; Tiggelaar, R. M. M.; Gardeniers, J. G. E. G. E.; Lefferts, L. Applicability of X-ray fluorescence spectroscopy as method to determine thickness and composition of stacks of metal thin films: A comparison with imaging and profilometry. Thin Solid Films 2012, 520, 1740-1744, doi:10.1016/j.tsf.2011.08.049.

91. Elam, W. T. T.; Shen, R. B.; Scruggs, B.; Nicolosi, J. Accuracy of Standardless FP Analysis of Bulk and Thin Film Samples Using a New Atomic Database. Adv. X-ray Anal. 2004, 47, 104-109.

92. Ager, F. J.; Ferretti, M.; Grilli, M. L.; Juanes, D.; Ortega-Feliu, I.; Respaldiza, M. A.; Roldán, C.; Scrivano, S. Reconsidering the accuracy of X-ray fluorescence and ion beam based methods when used to measure the thickness of ancient gildings. Spectrochim. Acta Part B At. Spectrosc. 2017, 135, 42-47, doi:10.1016/j.sab.2017.06.017.

93. Kolbe, M.; Beckhoff, B.; Krumrey, M.; Ulm, G. Thickness determination for $\mathrm{Cu}$ and Ni nanolayers: Comparison of completely reference-free fundamental parameter-based X-ray fluorescence analysis and Xray reflectometry. Spectrochim. Acta Part B At. Spectrosc. 2005, 60, 505-510, doi:10.1016/j.sab.2005.03.018. 
94. Queralt, I.; Ibañez, J.; Marguí, E.; Pujol, J. Thickness measurement of semiconductor thin films by energy dispersive X-ray fluorescence benchtop instrumentation: Application to GaN epilayers grown by molecular beam epitaxy. Spectrochim. Acta Part B At. Spectrosc. 2010, 65, 583-586, doi:10.1016/j.sab.2010.05.008.

95. XRMC Available online: https://github.com/golosio/xrmc/wiki.

96. XMI-MSIM Available online: https:/github.com/tschoonj/xmimsim/wiki.

97. Xraylib Available online: https://github.com/tschoonj/xraylib/wiki.

98. Schoonjans, T.; Brunetti, A.; Golosio, B.; Sanchez Del Rio, M.; Solé, V. A.; Ferrero, C.; Vincze, L. The xraylib library for X-ray-matter interactions. Recent developments. Spectrochim. Acta - Part B At. Spectrosc. 2011, 66, 776-784, doi:10.1016/j.sab.2011.09.011.

99. Golosio, B.; Schoonjans, T.; Brunetti, A.; Oliva, P.; Masala, G. L. Monte Carlo simulation of X-ray imaging and spectroscopy experiments using quadric geometry and variance reduction techniques. Comput. Phys. Commun. 2014, 185, 1044-1052, doi:10.1016/j.cpc.2013.10.034.

100. Schiavon, N.; de Palmas, A.; Bulla, C.; Piga, G.; Brunetti, A. An Energy-Dispersive X-Ray Fluorescence Spectrometry and Monte Carlo simulation study of Iron-Age Nuragic small bronzes ("Navicelle") from Sardinia, Italy. Spectrochim. Acta Part B At. Spectrosc. 2016, 123, 42-46, doi:10.1016/j.sab.2016.07.011.

101. Brunetti, A.; Fabian, J.; La Torre, C. W.; Schiavon, N. A combined XRF/Monte Carlo simulation study of multilayered Peruvian metal artifacts from the tomb of the Priestess of Chornancap. Appl. Phys. A 2016, 122, 571, doi:10.1007/s00339-016-0096-6.

102. Bottaini, C. E.; Brunetti, A.; Montero-Ruiz, I.; Valera, A.; Candeias, A.; Mirão, J. Use of Monte Carlo Simulation as a Tool for the Nondestructive Energy Dispersive X-ray Fluorescence (ED-XRF) Spectroscopy Analysis of Archaeological Copper-Based Artifacts from the Chalcolithic Site of Perdigões, Southern Portugal. Appl. Spectrosc. 2018, 72, 17-27, doi:10.1177/0003702817721934.

103. Barcellos Lins, S. A.; Ridolfi, S.; Gigante, G. E.; Cesareo, R.; Albini, M.; Riccucci, C.; di Carlo, G.; Fabbri, A.; Branchini, P.; Tortora, L. Differential X-Ray Attenuation in MA-XRF Analysis for a Non-invasive Determination of Gilding Thickness. Front. Chem. 2020, 8, 1-9, doi:10.3389/fchem.2020.00175.

104. Cesareo, R. Gold, gildings, and tumbaga from the Moche tomb of the Lady of Cao: An EDXRF test for the internal ratio method. X-Ray Spectrom. 2019, 48, 202-207, doi:10.1002/xrs.3021.

105. Cesareo, R.; Franco Jordan, R.; Fernandez, A.; Bustamante, A.; Fabian, J.; del Pilar Zambrano, S.; Azeredo, S.; Lopes, R. T.; Ingo, G. M.; Riccucci, C.; Di Carlo, G.; Gigante, G. E. Analysis of the spectacular gold and silver from the Moche tomb 'Señora de Cao.' X-Ray Spectrom. 2016, 45, 138-154, doi:10.1002/xrs.2680.

106. Cesareo, R.; de Assis, J. T.; Roldán, C.; Bustamante, A. D.; Brunetti, A.; Schiavon, N. Multilayered samples reconstructed by measuring $\mathrm{K} \alpha / \mathrm{K} \beta$ or $\mathrm{L} \alpha / \mathrm{L} \beta$ X-ray intensity ratios by EDXRF. Nucl. Instruments Methods Phys. Res. Sect. B Beam Interact. with Mater. Atoms 2013, 312, 15-22, doi:10.1016/j.nimb.2013.06.019.

107. Cesareo, R.; Bustamante, A.; Fabian, J.; Calza, C.; Dos Anjos, M.; Lopes, R. T.; Elera, C.; Shimada, I.; Curay, V.; Rizzutto, M. A. Energy-dispersive X-ray fluorescence analysis of a pre-Columbian funerary gold mask from the Museum of Sicán, Peru. X-Ray Spectrom. 2010, 39, 122-126, doi:10.1002/xrs.1192.

108. Cesareo, R. Non-destructive EDXRF-analysis of the golden haloes of Giotto's frescos in the Chapel of the Scrovegni in Padua. Nucl. Instruments Methods Phys. Res. Sect. B Beam Interact. with Mater. Atoms 2003, 211, 133-137, doi:10.1016/S0168-583X(03)01165-0.

109. Porcinai, S.; Ferretti, M. X-ray fluorescence-based methods to measure the thickness of protective organic coatings on ancient silver artefacts. Spectrochim. Acta - Part B At. Spectrosc. 2018, 149, 184-189, doi:10.1016/j.sab.2018.08.001.

110. de Almeida, E.; Melquiades, F. L.; Marques, J. P. R.; Marguí, E.; de Carvalho, H. W. P. Determination of the polymeric thin film thickness by energy dispersive X-ray fluorescence and multivariate analysis. Spectrochim. Acta Part B At. Spectrosc. 2020, 167, 105818, doi:10.1016/j.sab.2020.105818.

111. West, M.; Ellis, A. T.; Streli, C.; Vanhoof, C.; Wobrauschek, P. 2017 atomic spectrometry update - a review of advances in X-ray fluorescence spectrometry and its special applications. J. Anal. At. Spectrom. 2017, 32, 1629-1649, doi:10.1039/C7JA90035J.

112. Vanhoof, C.; Bacon, J. R.; Ellis, A. T.; Vincze, L.; Wobrauschek, P. 2018 atomic spectrometry update - a review of advances in X-ray fluorescence spectrometry and its special applications. J. Anal. At. Spectrom. 2018, 33, 1413-1431, doi:10.1039/C8JA90030B.

113. Vanhoof, C.; Bacon, J. R.; Ellis, A. T.; Fittschen, U. E. A.; Vincze, L. 2019 atomic spectrometry update - a review of advances in X-ray fluorescence spectrometry and its special applications. J. Anal. At. Spectrom. 2019, 34, 1750-1767, doi:10.1039/C9JA90042J. 
114. Castaing, R. Application of Electron Probes to Local Chemical and Crystallographic Analysis, Ph.D. Thesis, University of Paris, Paris, France, 1951.

115. Richter, S.; Pinard, P. T. Combined EPMA, FIB and Monte Carlo simulation: a versatile tool for quantitative analysis of multilayered structures. IOP Conf. Ser. Mater. Sci. Eng. 2016, 109, 012014, doi:10.1088/1757899X/109/1/012014.

116. Ortel, E.; Hertwig, A.; Berger, D.; Esposito, P.; Rossi, A. M. A. M.; Kraehnert, R.; Hodoroaba, V. D. V.-D. V. D. New Approach on Quantification of Porosity of Thin Films via Electron-Excited X-ray Spectra. Anal. Chem. 2016, 88, 7083-7090, doi:10.1021/acs.analchem.6b00847.

117. Eggert, F. EDX-spectra simulation in electron probe microanalysis. Optimization of excitation conditions and detection limits. Microchim. Acta 2006, 155, 129-136, doi:10.1007/s00604-006-0530-0.

118. Armigliato, A. Thin film X-ray microanalysis with the analytical electron microscope. J. Anal. At. Spectrom. 1999, 14, doi:10.1039/a806757k.

119. Christien, F.; Pierson, J. F.; Hassini, A.; Capon, F.; Le Gall, R.; Brousse, T. EPMA-EDS surface measurements of interdiffusion coefficients between miscible metals in thin films. Appl. Surf. Sci. 2010, 256, 1855-1860, doi:10.1016/j.apsusc.2009.10.019.

120. Pascual, R.; Cruz, L. R. R.; Ferreira, C. L. L.; Gomes, D. T. T. Thin film thickness measurement using the energy-dispersive spectroscopy technique in a scanning electron microscope. Thin Solid Films 1990, 185, 279-286, doi:10.1016/0040-6090(90)90092-R.

121. Microbeam and Nanobeam Analysis; Benoit, D., Bresse, J.-F., Van't dack, L., Werner, H., Wernisch, J., Eds.; Springer Vienna: Vienna, 1996; ISBN 978-3-211-82874-8.

122. Waldo, R. A.; Militello, M. C.; Gaarenstroom, S. W. Quantitative thin-film analysis with an energydispersive x-ray detector. Surf. Interface Anal. 1993, 20, doi:10.1002/sia.740200204.

123. Gauvin, R. Quantitative X-ray microanalysis of heterogeneous materials using Monte Carlo simulations. Microchim. Acta 2006, 155, doi:10.1007/s00604-006-0509-x.

124. Sokolov, S. A.; Kelm, E. A.; Milovanov, R. A.; Abdullaev, D. A.; Sidorov, L. N. Non-destructive determination of thickness of the dielectric layers using EDX. In Proceedings of SPIE - The International Society for Optical Engineering; Lukichev, V. F., Rudenko, K. V., Eds.; 2016; Vol. 10224, p. 1022426.

125. Stenberg, G.; Boman, M. Thickness measurement of light elemental films. Diam. Relat. Mater. 1996, 5, 14441449, doi:10.1016/S0925-9635(96)00563-8.

126. Willich, P.; Obertop, D. Composition and thickness of submicron metal coatings and multilayers on $\mathrm{Si}$ determined by EPMA. Surf. Interface Anal. 1988, 13, 20-24, doi:10.1002/sia.740130106.

127. Hunger, H. -J. -J; Baumann, W.; Schulze, S. A new method for determining the thickness and composition of thin layers by electron probe microanalysis. Cryst. Res. Technol. 1985, 20, 1427-1433, doi:10.1002/crat.2170201102.

128. Ares, J. R.; Pascual, A.; Ferrer, I. J.; Sánchez, C. A methodology to reduce error sources in the determination of thin film chemical composition by EDAX. Thin Solid Films 2004, 450, doi:10.1016/j.tsf.2003.10.073.

129. Sempf, K.; Herrmann, M.; Bauer, F. First results in thin film analysis based on a new EDS software to determine composition and/or thickness of thin layers on substrates. In EMC 2008 14th European Microscopy Congress 1-5 September 2008, Aachen, Germany; Springer, 2008; pp. 751-752.

130. Hodoroaba, V.-D.; Kim, K. J.; Unger, W. E. S. Energy dispersive electron probe microanalysis (ED-EPMA) of elemental composition and thickness of Fe-Ni alloy films. Surf. Interface Anal. 2012, 44, doi:10.1002/sia.4975.

131. Canli, S. Thickness Analysis of Thin Films By Energy Dispersive X-Ray Spectroscopy, 2010.

132. Moller, A.; Weinbruch, S.; Stadermann, F. J.; Ortner, H. M.; Neubeck, K.; Balogh, A. G.; Hahn, H. Accuracy of film thickness determination in electron-probe microanalysis. Mikrochim. Acta 1995, 119, 41-47, doi:10.1007/BF01244852.

133. Procop, M.; Radtke, M.; Krumrey, M.; Hasche, K.; Schädlich, S.; Frank, W. Electron probe microanalysis (EPMA) measurement of thin-film thickness in the nanometre range. Anal. Bioanal. Chem. 2002, 374, 631634, doi:10.1007/s00216-002-1514-5.

134. Campos, C. S.; Coleoni, E. A.; Trincavelli, J. C.; Kaschny, J.; Hubbler, R.; Soares, M. R. F.; Vasconcellos, M. A. Z. Metallic thin film thickness determination using electron probe microanalysis. X-Ray Spectrom. 2001, 30, 253-259, doi:10.1002/xrs.495. 
135. Libo, Z.; Shengxiang, B.; Rong, W.; Shilan, L.; Lili, M.; Dechun, L.; Zhuang, L.; Bao, S.; Wang, R.; Li, S.; Ma, L.; Lv, D. Thin film thickness measurement using electron probe microanalyzer. In 2009 International Conference on Applied Superconductivity and Electromagnetic Devices; 2009; pp. 142-144.

136. Osada, Y. Electron probe microanalysis (EPMA) measurement of aluminum oxide film thickness in the nanometer range on aluminum sheets. X-Ray Spectrom. 2005, 34, 92-95, doi:10.1002/xrs.797.

137. Merlet, C. Thin Film Quantification by EPMA: Accuracy of Analytical Procedure. Microsc. Microanal. 2006, 12, 842-843, doi:10.1017/S1431927606062611.

138. August, H.; Wernisch, J. A Method for Determining the Mass Thickness of Thin Films Using Electron Probe Microanalysis. Scanning 1987, 9.

139. Shang, Y.; Guo, Y.; Liu, Z.; Xu, L. An EPMA software for determination of thin metal film thickness and it's application. Jinshu Xuebao/Acta Metall. Sin. 1997, 33.

140. Watanabe, M.; Horita, Z.; Nemoto, M. Absorption correction and thickness determination using the zeta factor in quantitative X-ray microanalysis. Ultramicroscopy 1996, 65, 187-198.

141. Bishop, H. E.; Poole, D. M. A simple method of thin film analysis in the electron probe microanalyser. $J$. Phys. D. Appl. Phys. 1973, 6, 1142-1158, doi:10.1088/0022-3727/6/9/318.

142. Rinaldi, R.; Llovet, X. Electron Probe Microanalysis: A Review of the Past, Present, and Future. Microsc. Microanal. 2015, 21, 1053-1069, doi:10.1017/S1431927615000409.

143. Colby, J. W. Quantitative Microprobe Analysis of Thin Insulating Films. Adv. X-ray Anal. 1967, 11, 287-305, doi:10.1154/S0376030800004924.

144. HUNGER, H. J. Thin Film Analysis by X-Ray Microanalysis Using Gaussian f (p z ) Curves. Scanning 1988, 10, 65-72.

145. STRATAGem - SAMx Available online: http://www.samx.com/index.html.en.

146. Kühn, J.; Hodoroaba, V.-D.; Linke, S.; Moritz, W.; Unger, W. E. S. Characterization of Pd-Ni-Co alloy thin films by ED-EPMA with application of the STRATAGEM software. Surf. Interface Anal. 2012, 44, 1456-1458, doi:10.1002/sia.4974.

147. Dumelié, N.; Benhayoune, H.; Balossier, G. TF_Quantif: A quantification procedure for electron probe microanalysis of thin films on heterogeneous substrates; 2007; ISBN 9781600214554.

148. Small World Available online: http://www.small-world.net/efs.htm.

149. Batanova, V. G.; Sobolev, A. V.; Kuzmin, D. V. Trace element analysis of olivine: High precision analytical method for JEOL JXA-8230 electron probe microanalyser. Chem. Geol. 2015, 419, 149-157, doi:10.1016/j.chemgeo.2015.10.042.

150. ThinFilmID - Oxford Instruments Available online: http://www.oxfordinstruments.cn/OxfordInstruments/media/nanoanalysis/brochures and thumbs/ThinFilmID_Brochure.pdf.

151. LayerProbe - Oxford Instruments Available online: https://www.oxfordinstruments.com/products/microanalysis/solutions/layerprobe.

152. pyPENELOPE Available online: http://pypenelope.sourceforge.net/.

153. Llovet, X.; Salvat, F. PENEPMA: A Monte Carlo Program for the Simulation of X-Ray Emission in Electron Probe Microanalysis. Microsc. Microanal. 2017, 23, 634-646, doi:10.1017/S1431927617000526.

154. Electron Beam Scattering Modeling Available online: http://montecarlomodeling.mcgill.ca/.

155. Gauvin, R.; Lifshin, E.; Demers, H.; Horny, P.; Campbell, H. Win X-ray: A new Monte Carlo program that computes X-ray spectra obtained with a scanning electron microscope. Microsc. Microanal. 2006, 12, 49-64, doi:10.1017/S1431927606060089.

156. Gauvin, R.; Michaud, P. MC X-Ray, a new monte carlo program for quantitative X-ray microanalysis of real materials. Microsc. Microanal. 2009, 15, 488-489, doi:10.1017/S1431927609092423.

157. Llovet, X.; Merlet, C. Electron Probe Microanalysis of Thin Films and Multilayers Using the Computer Program XFILM. Microsc. Microanal. 2010, 16, 21-32, doi:10.1017/S1431927609991218.

158. CASINO Available online: https://www.gel.usherbrooke.ca/casino/index.html.

159. Demers, H.; Poirier-Demers, N.; Couture, A. R.; Joly, D.; Guilmain, M.; De Jonge, N.; Drouin, D. Threedimensional electron microscopy simulation with the CASINO Monte Carlo software. Scanning 2011, 33, 135-146, doi:10.1002/sca.20262.

160. Hovington, P.; Drouin, D.; Gauvin, R. CASINO: A new Monte Carlo code in C language for electron beam interaction - Part I: Description of the program. Scanning 1997, 19, 1-14, doi:10.1002/sca.4950190101. 
161. Drouin, D.; Couture, A. R.; Joly, D.; Tastet, X.; Aimez, V.; Gauvin, R. CASINO V2.42 - A Fast and Easy-touse Modeling Tool for Scanning Electron Microscopy and Microanalysis Users. Scanning 2007, 29, 92-101, doi:10.1002/sca.20000.

162. CalcZAF Available online: http://www.probesoftware.com/Technical.html.

163. Armstrong, J. T.; Donovan, J.; Carpenter, P. CALCZAF, TRYZAF and CITZAF: The Use of MultiCorrection-Algorithm Programs for Estimating Uncertainties and Improving Quantitative X-ray Analysis of Difficult Specimens. Microsc. Microanal. 2013, 19, 812-813, doi:10.1017/s1431927613006053.

164. Ritchie, N. W. M. NIST DTSA-II Available online: http://www.cstl.nist.gov/div837/837.02/epq/dtsa2/.

165. Ritchie, N. W. m. M. Spectrum Simulation in DTSA-II. Microsc. Microanal. 2009, 15, 454-468, doi:10.1017/S1431927609990407.

166. Ritchie, N. W. M. Efficient Simulation of Secondary Fluorescence Via NIST DTSA-II Monte Carlo. Microsc. Microanal. 2017, 23, 618-633, doi:10.1017/S1431927617000307.

167. Salvat, F.; Fernández-Varea, J. M.; Sempau, J. PENELOPE - 2006 : A Code System for Monte Carlo Simulation of Electron and Photon Transport; OECD/NEA Data Bank, 2006; ISBN 9264023011.

168. Katz, L.; Penfold, A. S. Range-energy relations for electrons and the determination of beta-ray end-point energies by absorption. Rev. Mod. Phys. 1952, 24, 28-44, doi:10.1103/RevModPhys.24.28.

169. Cockett, G. H.; Davis, C. D. Coating thickness measurement by electron probe microanalysis. Br. J. Appl. Phys. 1963, 14, 813-816, doi:10.1088/0508-3443/14/11/320.

170. Matthews, M. B.; Kearns, S. L.; Buse, B. The Accuracy of Al and Cu Film Thickness Determinations and the Implications for Electron Probe Microanalysis. Microsc. Microanal. 2018, 24, 83-92, doi:10.1017/S1431927618000193.

171. Campos, C. S.; Vasconcellos, M. A. Z.; Llovet, X.; Salvat, F. Thickness Determination of Ultra-Thin Films on Si Substrates by EPMA. Microchim. Acta 2004, 145, 13-17, doi:10.1007/s00604-003-0120-3.

172. Chininis, J.; Whiteside, P.; Hunt, H. K. Metal-clad waveguide characterization for contact-based light transmission into tissue. In Photonic Therapeutics and Diagnostics XII; Choi, B., Kollias, N., Zeng, H., Kang, H. W., Wong, B. J. F., Ilgner, J. F., Tearney, G. J., Gregory, K. W., Marcu, L., Skala, M. C., Campagnola, P. J., Mandelis, A., Morris, M. D., Eds.; 2016; Vol. 9689, p. 968915.

173. Stanford, J. A.; Teslich, N.; Donald, S.; Saw, C. K.; Gollott, R.; Dinh, L. N. Measurement of PuO2 film thickness by electron probe microanalysis (EPMA) calibration curve method. J. Nucl. Mater. 2020, 530, 151968, doi:10.1016/j.jnucmat.2019.151968.

174. Bastin, G. F. F.; Heijligers, H. J. M. M. A systematic database of thin-film measurements by EPMA Part I Aluminum films. X-Ray Spectrom. 2000, 29, 212-238, doi:10.1002/(SICI)1097-4539(200005/06)29:3<212::AIDXRS422>3.0.CO;2-K.

175. Bastin, G. F.; Heijligers, H. J. M. A systematic database of thin-film measurements by EPMA Part II Palladium films. X-Ray Spectrom. 2000, 29, 373-397, doi:10.1002/1097-4539(200009/10)29:5<373::AIDXRS442>3.0.CO;2-S.

176. Merlet, C. Analytical Multilayer Model Revisited for High Atomic Numbers at Low Voltage. Microsc. Microanal. 2014, 20, 736-737, doi:10.1017/S1431927614005406.

177. Merlet, C. Quantitative X-ray Microanalysis of Multi-layered Specimens: Capability and Accuracy. Microsc. Microanal. 2013, 19, 1240-1241, doi:10.1017/S1431927613008192.

178. Pazzaglia, A.; Maffini, A.; Dellasega, D.; Lamperti, A.; Passoni, M. Reference-free evaluation of thin films mass thickness and composition through energy dispersive X-ray spectroscopy. Mater. Charact. 2019, 153, 92-102, doi:10.1016/j.matchar.2019.04.030.

179. Darznek, S. A.; Kuzin, A. Y.; Mityukhlyaev, V. B.; Stepovich, M. A.; Todua, P. A.; Filippov, M. N. Measurement of the Thickness Nonuniformity of Nanofilms Using an Electron Probe Method. Meas. Tech. 2016, 59, 822-825, doi:10.1007/s11018-016-1051-9.

(C) 2020 by the authors. Submitted for possible open access publication under the terms and conditions of the Creative Commons Attribution (CC BY) license (http://creativecommons.org/licenses/by/4.0/). 